\title{
PYROLYSIS OF BIOMASS IN THE ROTATING CONE REACTOR: MODELLING AND EXPERIMENTAL JUSTIFICATION
}

\author{
B. M. WAGENAAR ${ }^{\dagger, *}$, W. PRINS ${ }^{\ddagger}$ and W. P. M. VAN SWAAIJ ${ }^{\ddagger}$ \\ ${ }^{\dagger}$ BTG Biomass Technology Group, Drienerlolaan 5, 7522 NB Enschede, The Netherlands and \\ ${ }^{\ddagger}$ Twente University of Technology, Postbus 217, 7500 AE Enschede, The Netherlands
}

(Received 25 May 1994)

\begin{abstract}
In the rotating cone reactor, wood particles fed to the bottom of the rotating cone, together with an excess of inert heat carrier particles, are converted while being transported spirally upwards along the cone wall. The cone geometry is specified by a top angle of $\pi / 2$ radians and a maximum diameter of $650 \mathrm{~mm}$. Products obtained from the flash pyrolysis of wood dust in a rotating cone reactor are non-condensible gases, bio-oil and char. This paper reports on results of computations and measurements to determine the influence of process parameters like the cone rotational speed $(6-15 \mathrm{~Hz})$, the reactor volume $(3-2001)$, the wood-dust feed rate $\left(1-3.5 \mathrm{~g} \mathrm{~s}^{-1}\right)$ and the reactor temperature $\left(550-700^{\circ} \mathrm{C}\right)$ on the product composition.

The experimental results are compared with predictions of an integrated reactor model which accounts for: (i) the type of particle flow in the reactor; (ii) the wood decomposition kinetics; (iii) the rate of heat transfer to the wood particles; (iv) the kinetics of gas phase reactions (tar cracking); and ( $v$ ) gas exchange with the space in which ash, char and partially unconverted wood is collected. For the conditions applied, the difference between predicted and measured weight fractions of gas, tar and char produced was always less than $10 \%$. It further appeared that the wood particles were always completely converted inside the reactor and that the product distribution is only affected by the gas-phase reaction kinetics and residence time. The gas-phase residence time is determined by the available reactor volume and the feed rate of the wood particles. At optimal reactor conditions, the tar yield is almost maximal ( $70 \%$ d.a.f. wood base).
\end{abstract}

\section{INTRODUCTION}

The rotating cone reactor is a newly developed reactor for pyrolysis of biomass to produce bio-oil with negligible char formation. A schematic representation of the reactor is presented in Fig. 1. Biomass particles (wood) and heat carrier particles (sand) are introduced near the bottom of the cone where the solids are mixed and transported upwards by the rotating action of the cone. In the novel pyrolysis reactor rapid heating and a short residence time of the solids can be realized. Biomass materials like wood, rice husks or even olive stones can be pulverized and fed to the rotating cone reactor. Flash heating of the biomass will prevent coke forming cracking reactions. The particles remain close to the hot rotating cone wall and experience a high heat transfer rate. Since no carrier gas is needed (cost-reducing) the pyrolysis products will be formed at high concentrations. Moreover, a small gas-phase volume inside the rotating cone is possible which reduces the gas-phase residence time in the reactor and thus reduces the amount of bio-oil cracking reactions.

Biomass consists of three major components: cellulose, hemi-cellulose and lignin. Cellulose is a straight and stiff molecule with a polymerization degree of approximately $10^{4}$ glucose units $\left(C_{6}\right.$ sugar $)$.

*To whom correspondence should be addressed.
Hemi-celluloses are polymers built of $C_{5}$ and $C_{6}$ sugars with a polymerization degree of approximately 200 sugar units. Lignin is a three-dimensional branched polymer formed of phenolic units. Due to the aromatic content of lignin, it degrades slowly on heating and contributes to a major fraction of the char formation. In addition to the major cell wall components like cellulose, hemi-cellulose and lignin, biomass often contains varying amounts of species called extractives. These extractives, which are soluble in polar or nonpolar solvents, consist of terpenes, fatty acids, aromatic compounds and volatile oils. The composition of various biomass materials is presented in Table 1.

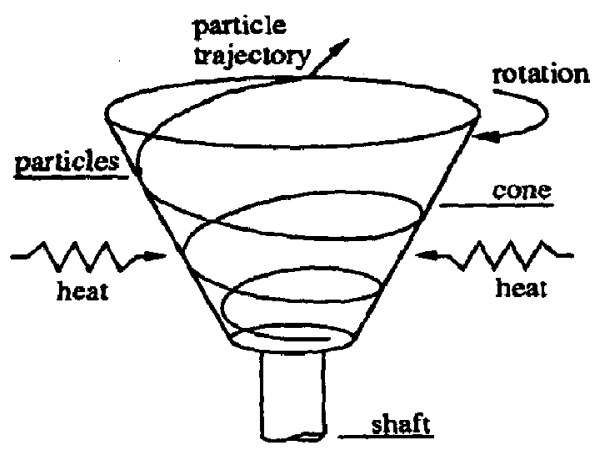

Fig. 1. The reactor principle. 
Table 1. Composition of different biomass types

\begin{tabular}{|c|c|c|c|c|c|c|}
\hline Biomass type & Cellulose & Hemi-cellulose & Lignin & Extractives & Ash & Ref. \\
\hline Soft wood & 41 & 24 & 28 & 2 & 0.4 & + \\
\hline Hard wood & 39 & 35 & 20 & 3 & 0.3 & + \\
\hline Pine bark & 34 & 16 & 34 & 14 & 2 & $\ddagger$ \\
\hline Straw (wheat) & 40 & 28 & 17 & 11 & 7 & + \\
\hline Rice husks & 30 & 25 & 12 & 18 & 16 & + \\
\hline Peat & 10 & 32 & 44 & 11 & 6 & 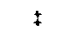 \\
\hline
\end{tabular}

'Shatizadeh (1985).

Arpiainen and Lappi (1989).

A detailed survey of available flash pyrolysis technologies is given by Bridgwater and Bridge (1991). These technologies include transport reactors in which the wood-dust particles enter a tube together with hot transport gas. At the end of the tube the char particles are separated from the pyrolysis vapours by a cyclone. The pyrolysis vapours are quenched immediately after the cyclone. Usually, the amount of wood which is converted into bio-oil varies between 50 and $60 \mathrm{wt} \%$ (Gorton et al., 1990; Graham et al., 1988). As shown by Roy et al. (1985), comparable bio-oil yields can be achieved with vacuum pyrolysis technologies; however, a large capacity vacuum pump is then required to maintain the vacuum condition in the reactor. Advantageous of the rotating cone technology is that similar bio-oil yields can be obtained at atmospheric pressure and without any product dilution. Apart from biomass conversion, other promising areas of application of the pyrolysis technologies are the pyrolysis of coal or oil shale, the thermal cracking of polymers and the concentration of slurries by evaporation.

This paper focuses on the presentation of a reactor model which should eventually predict the pyrolysis product distribution for a wide range of conditions. Such a model is a valuable tool for the interpretation of the present and future experiments. In this study, only a limited number of experiments have been carried out and compared with model predictions.

The overall reactor model consists of three parts which will be described in detail in the following sections: (i) the single particle flow model; (ii) the single particle conversion model; and (iii) the 2-CISTR gas-phase model.

A particle flow model is needed to predict the particle residence time in the reactor and to establish which correlation should be used for the coefficient of heat transfer to the particle. When all this is known, the degree of wood conversion in the reactor as well as the production rate of vapours can be calculated with the particle conversion model which includes the wood decomposition kinetics. Finally, the gas-phase model is meant to predict the gas composition in the reactor outlet on the basis of known kinetics for secondary tar cracking and the gas-phase residence time. This residence time is equal to the ratio of gas-phase volume over the production rate of vapours derived from the single particle conversion model.

\section{PARTICLE FLOW MODELS}

Direct observation of moving wood dust in the hot rotating cone reactor is hindered because the reactor construction is inacressible at high temperature and also because of the fouling action of the pyrolysis vapours. However, experiments at cold flow conditions with strobe-illumination of the particles clearly revealed the solids flow behaviour in the rotating cone by visual inspection of this flow. Three types of solids flow behaviour have been identified under cold flow conditions, depending on the type of feedstock used. It was observed that PVC, sand and glass particles exhibit a bouncing flow behaviour. But wood dust appeared to slide over the conical surface at the same conditions, while mud or fluffy material tends to stick to the cone wall.

An unknown wood-dust flow may cause a large error in the prediction of the pyrolysis product distribution. If, for instance, the wood dust moves very rapidly through the reactor, the wood-dust conversion can be limited. On the other hand, complete wooddust conversion is always achieved if the wood dust sticks to the cone wall. According to the cold flow observations, three wood-dust dynamic models are proposed. The first model calculates the motion of bouncing sand particles and assumes that the wood dust follows the sand flow exactly (equal local velocities for all the particles). The momentum coupling between the particles and the gas phase can result in the formation of an emulsion phase in which the small biomass particles and the sand particles have similar velocities. In this model the sand serves as exemplary material for the wood-dust flow. The second model assumes a sliding behaviour of the wood dust along the reactor walls. In this case, the bouncing sand particles are supposed to have no effect at all on the wood-dust motion. The last model assumes sticking of the wood-dust particles to the cone wall at pyrolysis conditions. Figure 2 illustrates the spherical co-ordinate system which has heen adapted for the model formulations presented hereafter.

\subsection{Bouncing flow}

The bouncing particle model is based on the assumption that the motion of wood dust is exactly the same as that of the bouncing sand particles. This type of particle flow can be conceived as a series of 


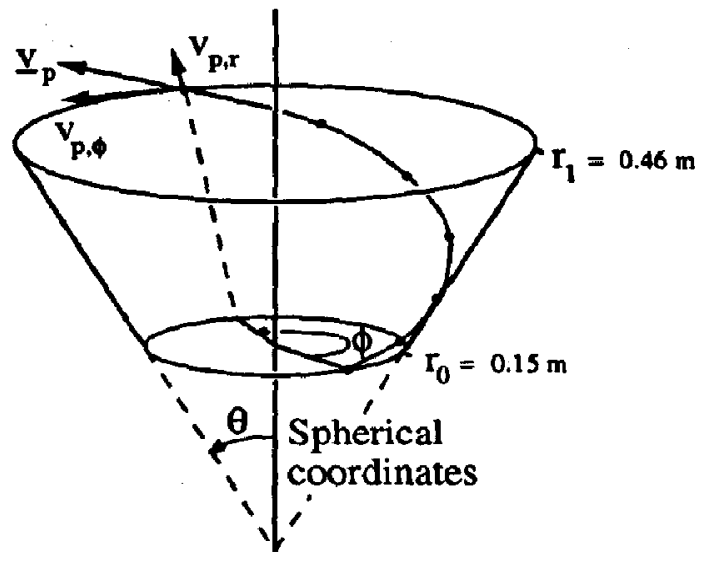

Fig. 2. The spherical coordinate system showing the velocity components and the particle trajectory along the cone wall.

particle-on-wall collisions and free flights of the particles through the gas phase.

In free flight, the motion of a particle through the gas phase can be described by Newton's second law of motion which states that the time rate of change of momentum is equal to force:

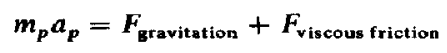

in which,

and

$$
F_{\text {gravitation }}=m_{p} g
$$

$$
F_{\text {viscous friction }}=C_{d} A_{p} \frac{1}{2} \rho_{g}\left|v_{v}-v_{p}\right|\left(v_{q}-v_{p}\right)
$$

A single isolated spherical particle experiences a drag force given by eq. (3). The drag coefficient presented in this equation was derived by Rowe (1961).

$$
C_{d}=\frac{24}{R e_{p}}\left(1+0.15 R e_{p}^{0.687}\right) \quad R e_{p}<1,000
$$

It has been assumed that the tangential gas phase velocity $v_{s}$ increases linearly with the distance between the two conical walls, viz. from a value zero at the non-rotating inner cone wall to a value $\omega R$ at the rotating one; these boundary values are evaluated on the basis of the no-slip condition. Although a gas-phase down-flow exists in the reactor due to the production of pyrolysis vapours, its value is small compared to the gas phase tangential velocity.

The particle position during a free-flight period can be calculated by step integration of eq. (1) with a fourth-order Runge-Kutta procedure. Ultimately, the free flight of a particle ends at the cone wall against which the particle collides. A collision description should be formulated now to calculate the change in particle velocity vector due to this collision. The position and updated velocity vectors after collision represent the starting condition of a new particle free-flight period.

Figure 3 illustrates the collision of a solid particle with a rigid wall. For reasons of physical invariance

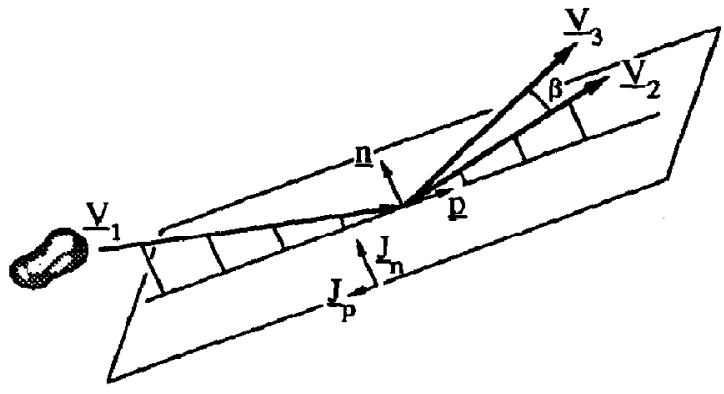

Fig. 3. Vector diagram which shows the change in the particle velocity vector during the collision of a moving particle with a stationary rigid wall.

the collision process is described in terms of particle motion relative to the wall:

$$
v_{i}=\left(v_{p}-v_{w}\right)
$$

When the particle hits the wall, it experiences an impulse with a component normal to the wall $J_{n}$ and a component in the tangential direction $J_{p}$. The particle momentum after the collision is given by eq. (6):

$$
m_{p}\left(v_{2}-v_{1}\right)=J_{n}+J_{p}
$$

The impulse in the direction normal to the cone wall is governed by the coefficient of restitution $\varepsilon$. A value of 0.95 for the restitution coefficient of sand on a flat steel wall has been adopted in the bouncing flow model, which is somewhat lower than the value 0.97 for spherical glass beads on a glass wall reported by Matsumoto and Saito (1970):

$$
J_{n}=(1+\varepsilon) m_{p}\left|\boldsymbol{n} \cdot v_{1}\right| \boldsymbol{n}
$$

The impulse in the direction tangential to the cone wall is governed by the kinetic coefficient of friction $\mu$. Experiments in our laboratory yielded a value for the wall friction constant $\mu$ of 0,4 for sand on steel which is comparable to the earlier reported values for the wall friction coefficient reported by Pilpel (1965) and Augenstein and Hogg (1974).

$$
J_{p}=-\mu(1+\varepsilon) m_{p}\left|n \cdot p_{1}\right| p
$$

A particle stops sliding $\left(v_{2} \cdot p=0\right)$ during the collision when $\left|p \cdot v_{1}\right|<\mu(1+\varepsilon)\left|n \cdot v_{1}\right|$, and in that case eq. (9) should be applied:

$$
J_{p}=-m_{p}\left(v_{1} \cdot \boldsymbol{p}\right) \boldsymbol{p}
$$

Upon introducing the values of the impulse components into eq. (6), the collision description predicts a damping of the normal particle velocity component which does not correspond to the undamped particle collision behaviour as observed in different experimental studies [see for example, Matsumoto and Saito (1970), Tsuji et al. (1989) and Wagenaar (1994a)]. This deviating collision behaviour originates from the roughness of the particle and wall surfaces and can be taken into account by giving the rebounding particle 
an additional angle of reflection named the deflection angle $\beta$. Because the velocity vector is only deflected by an angle $\beta$, the absolute velocity remains unchanged in the collision process, or $\left|v_{2}\right|=\left|v_{3}\right|$. After accounting for this deflection (also indicated in Fig. 3), the velocity vector of the rebounded particle can now be calculated with eq. (10) which has been derived from simple goniometry:

$$
\begin{aligned}
v_{3}= & {\left[\cos \beta-\frac{\left|\boldsymbol{n} \cdot v_{2}\right|}{\left|\boldsymbol{p} \cdot v_{2}\right|} \sin \beta\right]\left(\boldsymbol{p} \cdot v_{2}\right) \boldsymbol{p} } \\
& +\left[\cos \beta+\frac{\left|\boldsymbol{p} \cdot v_{2}\right|}{\left|\boldsymbol{n} \cdot v_{2}\right|} \sin \beta\right]\left(\boldsymbol{n} \cdot v_{2}\right) \boldsymbol{n}
\end{aligned}
$$

\subsection{Sliding flow}

Particles which slide over the cone wall should obey again Newton's second law of motion which states that the sum of all forces acting on a particle is equal to the time rate of change of particle momentum, given now by eq. (11).

$$
\begin{aligned}
m_{p} a_{p}= & F_{\text {gravitation }}+F_{\text {wall friction }} \\
& +F_{\text {viscous friction }}+F_{\text {normal }}
\end{aligned}
$$

If compared to eq. (1), the formulation of Newton's second law of motion is now extended with two additional terms, viz. the particle-on-wall friction force (12) and the normal force (13). A sketch of the sliding situation is given in Fig. 4.

$$
\begin{gathered}
F_{\text {gravitation }}=m_{p} g \\
F_{\text {viscous friotion }}=C_{d} A_{p} \frac{1}{2} \rho_{\theta}\left|v_{\theta}-v_{p}\right|\left(v_{\theta}-v_{p}\right) \\
F_{\text {wall friction }}=-\mu N_{\theta} \frac{\left(v_{w}-v_{p}\right)}{\left|v_{w}-v_{p}\right|} \\
F_{\text {normal }}=N_{\theta} e_{\theta}
\end{gathered}
$$

The wall exerts a coulomb frictional force on the sliding particle [eq. (12)]; its value is proportional to the normal force $N_{\theta}$ that acts on the particle. In the previous section the value of the wall friction proportionality constant $\mu$ for sand has been mentioned already. In addition to the coulomb friction a viscous friction force acts on the particle which is proportional to the velocity difference between particle and gas phase. The drag coefficient in eq. (3) is supposed to be the same as the one for an isolated single particle

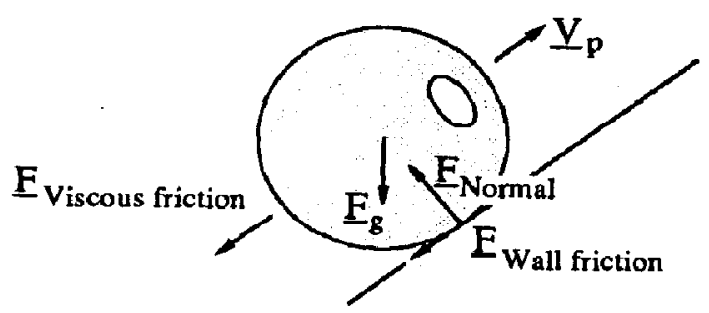

Fig. 4. Vector diagram of the forces that act on a particle which slides over a rigid wall. given already by eq. (4). Ambari et al. (1984) showed that the viscous force required to drag a sphere through a quiescent Newtonian liquid at low Reynolds numbers (approximately $10^{-3}$ ) can become three times larger than when this sphere slides along a solid wall. For this work the drag coefficient has not been modified to take such wall effects into account because of the large particle Reynolds numbers (approximately 1) encountered. As a consequence, the model prediction of the wood-dust residence time and conversion should be considered as conservative estimates. The value of the normal force $N_{\theta}$ is such that the $\theta$-component of the force balance (11) is satisfied under the condition that the particle velocity component normal to the cone wall is exactly zero $\left(v_{\theta}=0\right)$. The $\theta$-component of eq. (11) is evaluated first which yields a value for the normal force $N_{\theta}$ [eq. (13)]. Then eqs (2), (12) and (3) can be solved. Equation (11) can be solved with a fourth-order Runge-Kutta procedure. Numerical simulation of the trajectory of a sliding particle based on this Runge-Kutta procedure gives the particle position and particle velocity at any point in time.

\subsection{Sticking particles}

A particle sticks to the cone wall if the wall friction coefficient $\mu$ exceeds the limiting value given by eq. (14).

$$
\mu=\tan \theta
$$

The angle $\theta$ in eq. (14) represents the angle between the cone wall and the vertical axis and is equal to half of the cone top angle. Equation (14) can be obtained by applying the force balance (11) for a sliding particle and subsequently solving this force balance for the conditions that the particle velocity is equal to the wall velocity, and that the particle-on-wall friction force is equal to the yield force given by eq. (12).

Formulation of the $\theta$-component of the particle force balance yields:

$$
N_{\theta}+m_{p} g_{\theta}=-m_{p} \cos \theta \frac{v_{\phi}^{2}}{r \sin \theta}
$$

while the $r$-component of the particle force balance is given by:

$$
\mu N_{\theta}-m_{p} g_{r}=-m_{p} \sin \theta \frac{v_{\phi}^{2}}{r \sin \theta}
$$

If the normal force $N_{\theta}$ is solved from eq. (15) and substituted in eq. (16) the force balance finally yields:

$$
\frac{v_{\phi}^{2}}{r \sin \theta}=g \frac{1+\mu \tan \theta}{\tan \theta-\mu}
$$

The left-hand side of eq. (17) is the minimum acceleration required for particle motion induced by the angular velocity of the cone wall. If the denominator of the right-hand side is cqual to zero the particles will stick to the cone wall regardless of the angular speed of the cone wall; this corresponds to the criterion given already in eq. (14). Wood-dust particles that stick to the reactor wall are completely 
pyrolysed and the remaining char may stick to the cone wall or be scoured from the reactor wall by the action of the bouncing sand particles. For a cone with a top angle of $\pi / 2$ radians the coefficient of friction $\mu$ of the sliding material should be less than 1 to prevent sticking of this material on the cone wall. If the value of the biomass friction coefficient $\mu$ is larger than 1 , sticking of this material on the cone wall occurs which is accompanied by a complete conversion of the biomass material in the reactor volume.

\section{PARTICLE CONVERSION MODEL}

Description of the single particle pyrolysis behaviour is based on knowledge of the relevant chemical and physical processes. In case of flash pyrolysis (small particles) the most important ones are heat transfer and the kinetics of the thermal decomposition. In fact, a single particle is coupled with its surroundings through the external pressure and the heat transferred to the particle. Pressure may affect the residence time of the primary produced pyrolysis vapours in the pores of a biomass particle. A relatively long residence time would result in further cracking of these vapours to gaseous components. However, at atmospheric pressure the residence time of the vapours in the small $(0.2 \mathrm{~mm})$ and open ( $50 \%$ void) biomass particle is sufficiently small to exclude such an effect. The vapours which are produced in the pores of the biomass particle induce a pressure driven convective flow in these pores on which a relatively small diffusion flow is added. Vapours released in the biomass pores during pyrolysis are the primary products of the thermal decomposition. Besides, the biomass particle is assumed to remain solid, with pores gradually increasing in size as the pore walls vaporize.

In the absence of any heat or mass transfer limitations, the decomposition of wood is usually described by a single first-order model for weight loss of the reacting aggregate:

$$
\frac{\mathrm{d} m_{w}}{\mathrm{~d} t}=-k_{1} m_{w}
$$

By using the definition of the wood conversion degree

$$
\xi_{w}=1-\frac{m_{w}}{m_{w, 0}}
$$

eq. (18) can be transformed to:

$$
\frac{\mathrm{d} \xi_{w}}{\mathrm{~d} t}=k_{1}\left(1-\xi_{w}\right)
$$

Equation (18) is the integral mass balance of a wood-dust particle, valid when temperature gradients inside the particle are absent. According to a study by Pyle and Zaror (1984) this is the case if the particle Biot number is smaller than 1. For the small particles used in this study the value of the Biot number is approximately 0.3 .

The overall first-order rate constant for wood decomposition $k_{1}$ can be derived from literature. Its value represents the contributions of conversion to char, tar and gas according to the reaction paths illustrated in Fig. 5 (Shatizadeh, 1985). Wagenaar and coworkers (1993) have reviewed the results of various kinetic studies, and measured $k_{1}$ values for pine wood in the temperature range from 280 to $600^{\circ} \mathrm{C}$. Due to the absence of external and particle internal heat transfer limitations for these measurements, the wood decomposition rate has been proven to be equal to the chemical reaction rate. Wagenaar and coworkers also measured the individual rates of formation of char, tar and gas in a special experiment by determining the mass yield of each product immediately after production (see Table 2). In the present particle conversion model, the above results of Wagenaar and coworkers have been used to calculate the rate of wood decomposition, as well as the rate of tar and gas
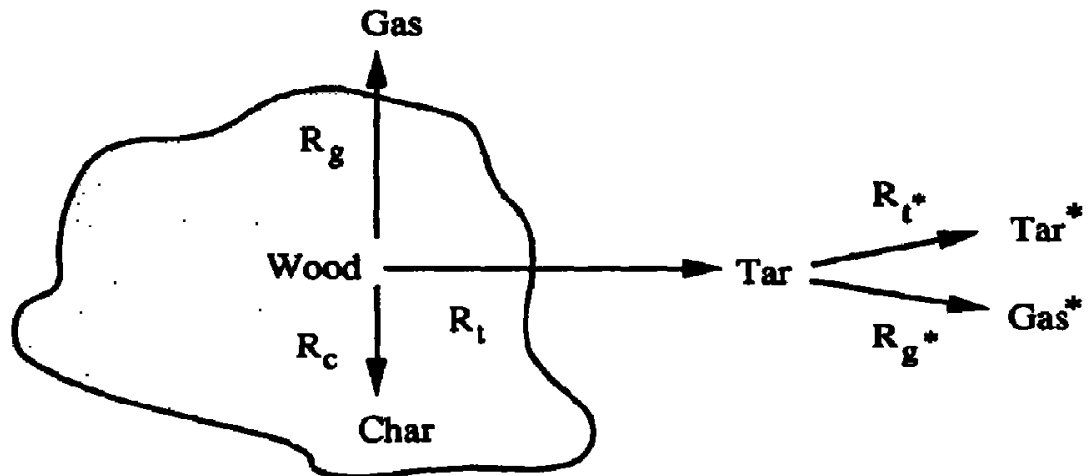

$$
\begin{aligned}
& \text { Primary wood decomposition } \\
& \text { reactions }
\end{aligned}
$$

Gas phase secondary tar cracking reactions

Fig. 5. The wood decomposition reaction paths consisting of paths leading to the primary products and the gas-phase secondary tar cracking reaction paths. 
Table 2. The pre-exponential constant and activation energy of the wood decomposition reactions

\begin{tabular}{lccc}
\hline Rcaction & $k_{\mathrm{o}}\left[\mathrm{s}^{-1}\right]$ & $E_{a}\left[\mathrm{~kJ} \mathrm{~mol}{ }^{-1}\right]$ & $\sigma_{i}\left(T,=600^{\circ} \mathrm{C}\right)$ \\
\hline$R_{1}$ & $1.4 \cdot 10^{10}$ & 150 & \\
$R_{\theta}$ & $1.11 \cdot 10^{11}$ & 177 & 0.182 \\
$R_{t}$ & $9.3 \cdot 10^{9}$ & 149 & 0.723 \\
$R_{c}$ & $1.4 \cdot 10^{9}$ & 150 & 0.095 \\
$R_{2}$ & $1.63 \cdot 10^{5}$ & 87.8 & \\
$R_{t}^{*}$ & $7.7 \cdot 10^{4}$ & 87.8 & 0.474 \\
$R_{a}^{*}$ & $8.6 \cdot 10^{4}$ & 87.8 & 0.526 \\
\hline
\end{tabular}

formation [eq. (21)]

$$
m_{t}=m_{w, o} \xi_{w, 1} \frac{k_{i}}{k_{1}}=m_{w, o} \xi_{w, 1} \sigma_{i} \quad i=\operatorname{tar}, \text { gas }
$$

However, with respect to the formation rate of char, it has been assumed that $R_{\mathrm{c}}$ is always one-tenth of the wood decomposition rate $R_{t}$ (see Table 2). This assumption is based on the observation that in all the rotating cone pyrolysis experiments approximately $10 \mathrm{wt} \%$ of the wood feedstock was converted to char, no matter what conditions had been applied.

The particle thermal energy balance [eq. (22)] is coupled to the mass balance [eq. (18)] by the reaction rate term appearing in both equations. It contains a heat accumulation term given by the left-hand side of eq. (22) and two terms in the right-hand side, one describing the thermal coupling between particle and surroundings and the other being the heat-of-reaction term. Just like eq. (18) this heat balance also belongs to a situation of uniform particle heating ( $\mathrm{Bi}<1$ ).

$$
\left(\rho_{w} C_{p, w}+\rho_{c} C_{p, c}\right) \frac{\mathrm{d} T_{p}}{\mathrm{~d} t}=\alpha_{p}\left(T_{g}-T_{p}\right) \frac{A_{p}}{V_{p}}-k_{1} \rho_{w} H_{r}
$$

Because wood gradually converts to char, both wood and char should be included in the change of thermal energy content, that is the left-hand side of the energy balance. The actual composition of a particle can be regarded as a mixture of these two components.

Simultaneous solution of eqs (20), (21) and (22) yields the particle temperature, the wood conversion, and the amounts of primary products released as a function of time. The only unknown parametcr left is $\alpha_{p}$, the coefficient of heat transfer to the particle.

The value of the heat transfer coefficient is determined by the hydrodynamic conditions inside the reactor. For an isolated single particle in an undisturbed gas flow the well known Ranz-Marshall correlation is normally used.

$$
N u_{p}=2+0.6 \operatorname{Re}_{p}^{0.50} \operatorname{Pr}^{0.33}, \quad N u_{p}=\frac{\alpha_{p} d_{p}}{\lambda_{g}}
$$

Results of a separate heat transfer study by Wagenaar et al. $(1994 \mathrm{~b}, \mathrm{c})$ indicate that this Ranz-Marshall correlation (1952) provides a fairly good prediction for heat transfer to glass particles flowing through the rotating cone reactor. Therefore, in this work the Ranz-Marshall correlation has been used in the model calculations for the bouncing-particle flow behaviour in which the wood-dust particles are supposed to follow the bulk flow of the additional sand particles (see Section 2.1).

In case of sliding wood-dust particles, the value of the heat transfer coefficient should be derived from another relationship, because of a different heat transfer mechanism. It can be obtained from the particle-to-wall heat transfer correlation given by Schlünder (1982) and Patton and coworkers (1986). The value of the thermal contact resistance length $\sigma$ under the actual pyrolysis conditions is equal to $0.1 \mu \mathrm{m}$.

$N u_{p}=\left(\frac{2 \sigma}{d_{p}}+1\right) \ln \left(\frac{d_{p}}{2 \sigma}+1\right)-1, \quad N u_{p}=\frac{\alpha_{p} d_{p}}{\lambda_{g}}$

Finally, for sticking wood-dust particles, no heat transfer correlation is required; neither the wood decomposition kinetics, nor the heating rate of the particles, can limit the particle conversion any more because they remain in the reactor all the time.

\section{GAS-PHASE REACTOR MODEL}

The gas-phase model is meant to describe the process of secondary tar cracking and to predict the composition of the gas mixture in the outlet of the reactor. A key parameter in the model is the gas-phase residence time which is determined by the production rate of pyrolysis vapours and the gas-phase volume involved. As illustrated in Fig. 6, the rotating cone reactor volume consists of a bottom volume and an annular cone volume. In this hot reactor volume wood particles decompose into the pyrolysis products gases, tars and char. These primary products released from the individual particles enter the gas-phase volume of the hot reactor at a flow rate of $\phi_{v 0} \mathrm{~m}^{3} \mathrm{~s}^{-1}$, indicated hereafter as the volumetric vapour production flow. In first approach, the gas phase is assumed to behave like a continuous, ideally stirred tank reactor (CISTR) due to the mixing action of the rotating cone. The mixing intensity is characterized by the ratio of "rotation frequency times reactor volume" over "the volumetric vapour production flow". For the experiments of this study the value of this ratio varies between 4 and 16 which in first instance seerns to be large enough to assume ideal mixing.

Figure 6 also shows the large gas-phase dead volume of the surrounding oven which serves as a collection chamber for ash, char and unconverted wood. It should be noticed that for incomplete biomass conversion in the reactor volume, a oneCISTR model might be insufficient to describe the secondary tar cracking process. In fact, when partially unconverted particles are transferred to the dead volume of the hot oven, the primary pyrolysis vapours will be released partially in this large volume and, because of their long residence time, be cracked largely 


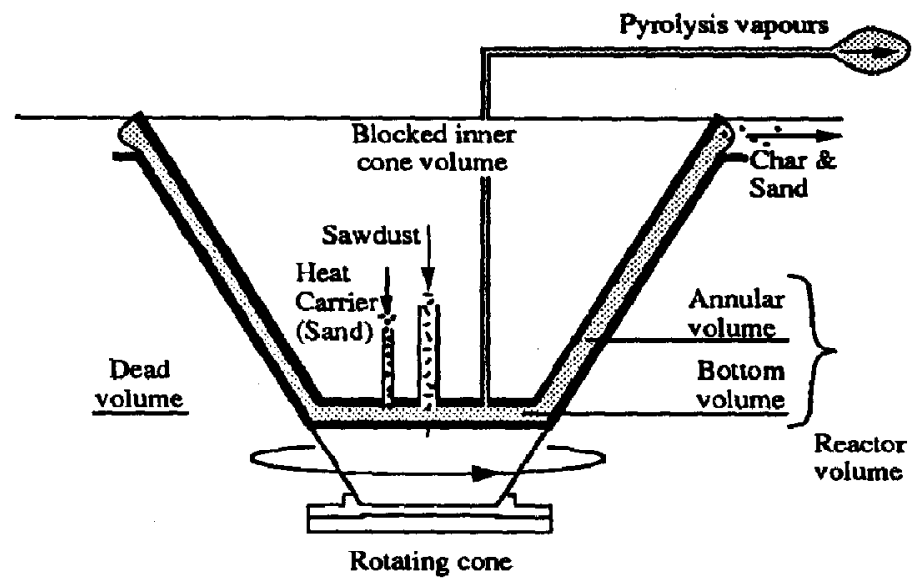

Fig. 6. Schematic arrangement of the rotating cone reactor which shows the reactor volume (bottom volume and annular cone volume) and the blocked inner cone volume.

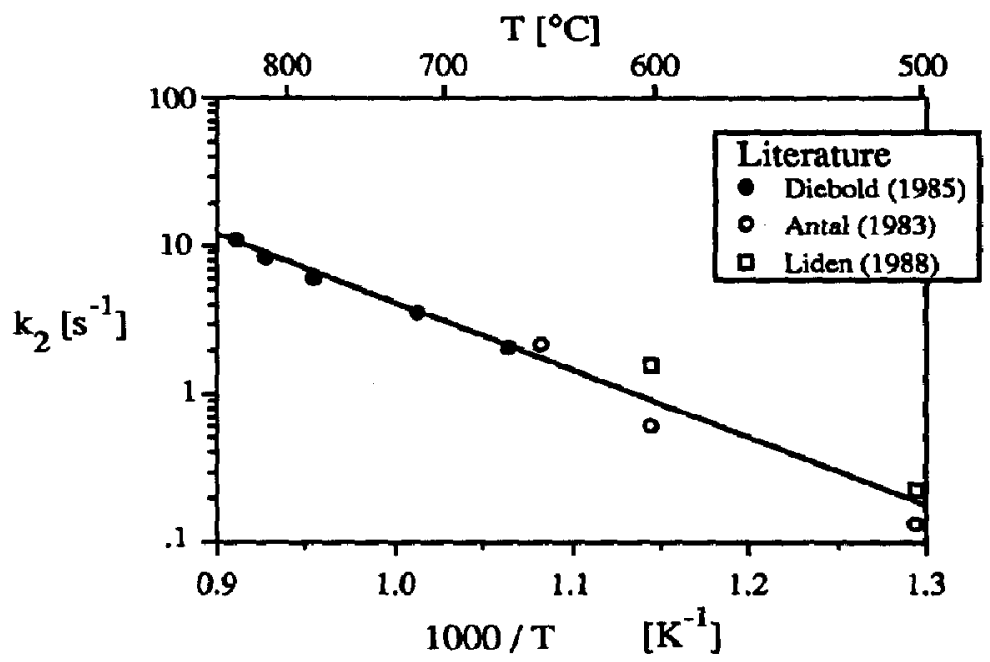

Fig. 7. The first-order rate constant of the secondary tar cracking reaction as a function of the reaction temperature (Wagenaar, 1994).

to secondary products. These cracked products must pass the cone reactor volume to reach the gas outlet tube of the set-up (see Figs 6 and 7). As a result, the yapours leaving the reactor are mixed with dead-volume products, and the final product gas becomes enriched with undesired secondary products.

In case of incomplete conversion inside the reactor, the total volumetric vapour production flow $\phi_{v 0}$ is divided into two parts, viz., the one of the cone reactor and the one created in the surrounding oven. The corresponding molar flow of primary produced tars and gases from wood-dust particles, being decomposed either in the reactor space or in the dead oven volume, can be calculated from eqs (25) and (26) respectively, if the degree of wood dust conversion $\xi_{m, 1}$ at the reactor exit (at $r=0.46 \mathrm{~m}$ ) is known:

$$
\begin{array}{ll}
R_{i, 1}=\frac{\sigma_{i} \xi_{w, 1} \phi_{m, w}}{M_{i}}\left[\mathrm{~mol}_{i} \mathrm{~s}^{-1}\right] & i=\mathrm{tar}, \text { gas } \\
R_{t, 2}=\frac{\sigma_{i}\left(1-\xi_{w, 1}\right) \phi_{m, w}}{M_{i}}\left[\mathrm{~mol}_{t} \mathrm{~s}^{-1}\right] & i=\mathrm{tar}, \text { gas }
\end{array}
$$

Obviously, one of the particle flow models must be used to determine the position of -the wood-dust particle as a function of time. Then, the single particle model provides the corresponding value of $\xi_{w 1}$. Arpiainen and Lappi (1989) measured the molecular weights of the pyrolysis products. They derived a molar mass equal to $32 \mathrm{kmol} \mathrm{kg}^{-1}$ for gas $\left(g, g^{*}\right)$ and an average molar mass equal to $162 \mathrm{kmol} \mathrm{kg}^{-1}$ for $\operatorname{tar}\left(t, t^{*}\right)$. 


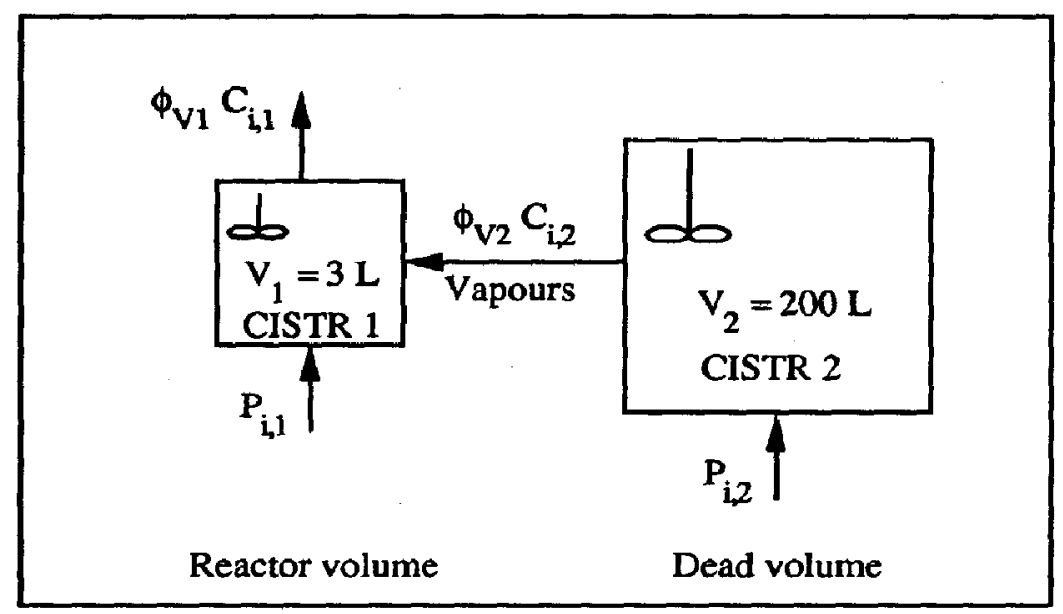

Fig. 8. The two CISTR-model for incomplete biomass conversion calculations.

The present gas-phase model is based on a twoCISTR concept; the first one is the rotating cone reactor, and the second is the large dead volume of the surrounding oven. A sketch of the two-CISTR concept is given in Fig. 8 . The belonging mass balances, assuming isothermal conditions and constant pressure in the gas phase, for all components are given hereafter:

CISTR 1, Reactor volume.

$$
\begin{aligned}
\phi_{V 1} C_{g, 1} & =\phi_{V 2} C_{g, 2}+R_{g, 1} \\
\phi_{V 1} C_{t, 1} & =\phi_{V 2} C_{t, 2}+R_{t, 1}-k_{2} C_{t, 1} V_{1} \\
\phi_{V 1} C_{g^{*}, 1} & =\phi_{V 2} C_{g^{*}, 2}+v_{\theta^{*}} \sigma_{g^{*}} k_{2} C_{t, 1} V_{1} \\
\phi_{V 1} C_{r^{*}, 1} & =\phi_{V 2} C_{r^{*}, 2}+v_{t^{*}} \sigma_{t^{*}} k_{2} C_{t, 1} V_{1} \\
C_{0} & =C_{g, 1}+C_{t, 1}+C_{g^{*}, 1}+C_{t^{*}, 1}
\end{aligned}
$$

CISTR 2, Dead volume.

$$
\begin{aligned}
\phi_{V 2} C_{g, 2} & =R_{g, 2} \\
\phi_{V 2} C_{t, 2} & =R_{t, 2}-k_{2} C_{t, 2} V_{2} \\
\phi_{V 2} C_{g^{*}, 2} & =v_{g^{*}} \sigma_{a^{*}} k_{2} C_{t, 2} V_{2} \\
\phi_{V 2} C_{t^{*}, 2} & =v_{t^{*}} \sigma_{\boldsymbol{t}^{*}} k_{2} C_{t, 2} V_{2} \\
C_{0} & =C_{g, 2}+C_{t, 2}+C_{g^{*}, 2}+C_{t^{*}, 2}
\end{aligned}
$$

The first-order tar cracking rate constant $k_{2}$ which is used in eqs (27) (36) is based on experimental results of Antal (1983), Diebold (1985) and Liden and coworkers (1988). These authors assumed a tar cracking rate expression which was first-order in the remaining tar mass. Their measured first-order rate constants as a function of the cracking temperature are presented in a single Arrhenius plot given in Fig. 7 . The activation energy and pre-exponential constant of the first-order tar cracking rate constant obtained from a best fit of the experimental data by Wagenaar and coworkers are listed in Table 2.
Equations (31) and (36) represent the state of constant molar concentration throughout the reactor volume according to the law for "ideal gases". Each CISTR description consists of five equations with one unknown volumetric outlet flow and four unknown molar concentrations at the reactor exit. The number of unknown variables is equal to the number of equations by which the system of equations that describes one CISTR can be solved once values of model parameters (like $R_{i}, k_{2}$, etc) are substituted. Finally, the weight fraction of each species can be calculated from the corresponding mass flows given by:

$$
\phi_{m, i}=C_{i} M_{i} \phi_{v}
$$

\section{EXPERIMENTAL}

It has been indicated already that the reactor is provided with an inner cone to reduce the reactor volume. An optimal reduction of reactor volume is needed to minimize the residence time of the produced gases and tars in the hot zone and suppress the tar cracking reactions. The volume of the present rotating cone reactor is 31 , composed of a bottom volume (1 1) and a conical annular volume (2 1). Figure 9 shows the spatial distribution of the reactor volume. All solids (char and sand) leave the cone at the largestdiameter position. Then the solids are collected in the dead volume of the surrounding oven which is equal to 2001 . A negligible vapour exchange between the reactor volume and the dead volume in the oven has been detected by a separate residence time distribution measurement in which $\mathrm{CO}$ was used as a tracer gas $\left(0.51 \mathrm{~s}^{-1}\right.$, independent of the cone rotational frequency $(5-15 \mathrm{~Hz}))$. The cone has a top angle of $\pi / 2 \mathrm{rad}$, a minimum diameter of $200 \mathrm{~mm}$ (bottom) and a maximum diameter of $650 \mathrm{~mm}$ (top). Measurement of the reactor temperature occurs by averaging of the inner cone temperature and the cone wall temperature. Usually, the difference between these temperatures is 


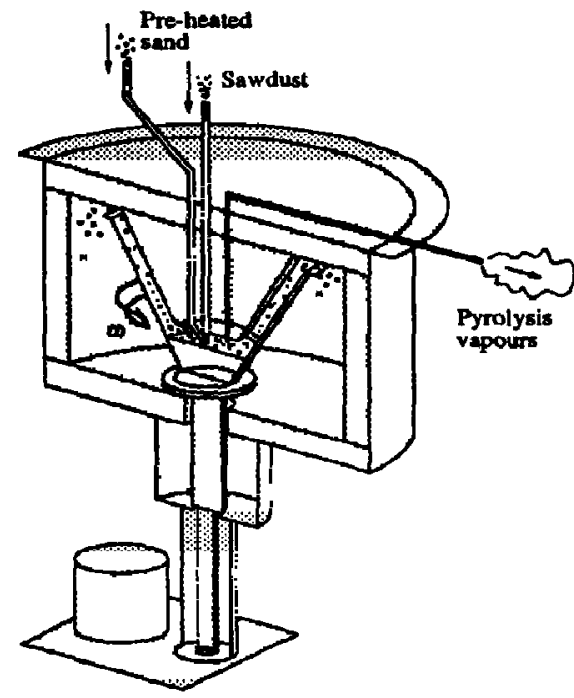

Fig. 9. Three-dimensional cross-sectional representation of the reactor geometry.

less than $10^{\circ} \mathrm{C}$. The temperatureof the inner cone is measured with a thermocouple clamped on the inner cone surface while the rotating cone wall temperature is recorded by a thermocouple which is positioned as close as possible $(5 \mathrm{~mm})$ near the outside of the rotating cone surface. This thermocouple is provided with a square cap $(50 \times 50 \times 5 \mathrm{~mm}$, cone wall material) to ensure a good radiative coupling between the rotating cone wall and the cap. Due to this radiative coupling, the temperature measured with this thermocouple is expected to be approximately equal to the cone wall temperature.

Although other types of biomass (for instance, oak wood and rice husks) have been thermally processed in the rotating cone reactor as well, results reported in this study mainly refer to pine wood as feedstock material. The wood chips are hammer-milled to yield dust with an average particle size of $200 \mu \mathrm{m}$. These small particles are introduced into the reactor with a vibratory feeder at a rate of approximately $2 \mathrm{~g} \mathrm{~s}^{-1}$. Apart from the wood dust, pre-heated sand is also fed into the reactor: it is meant to act as an inert heat carrier with the additional advantage of promoting the flow of wood dust. In cvery experiment, sand was added to the biomass flow with a feed rate of $31 \pm 1 \mathrm{~g} \mathrm{~s}^{-1}$. The sand particles have a diameter of approximately $1 \mathrm{~mm}$ and an inlet temperature equal to the reactor temperature. Measured properties of the different feedstocks used are listed in Table 3. The oxygen content of the different biomass types has been determined by difference.

Before the start of each experiment the solids feeders are charged and the reactor is heated to a constant reactor temperature. If this temperature has been attained, the experiment starts by simultaneously introducing the sand and wood-dust flows into the hot reactor. Within a second of the solids entering
Table 3. Properties of the biomass feedstock

\begin{tabular}{cccc}
\hline Property & Pine wood & Oak wood & Rice husks \\
\hline Composition (wt $\%$ ) & & & \\
Elements & $\mathrm{CH}_{1.6} \mathrm{O}_{0.7}$ & $\mathrm{CH}_{1.6} \mathrm{O}_{0.8}$ & $\mathrm{CH}_{1.4} \mathrm{O}_{0.7}$ \\
Volatile (ISO 562) & 83.84 & 80.51 & 64.98 \\
Water (ISO 589) & 6.40 & 8.91 & 9.04 \\
Ash (ISO 1171) & 0.26 & 0.31 & 18.06 \\
Diameter range & & & \\
0-100 $\mu \mathrm{m}$ & 0.662 & 0.278 & 0.942 \\
$100-212 \mu \mathrm{m}$ & 0.305 & 0.326 & 0.058 \\
$212-355 \mu \mathrm{m}$ & 0.033 & 0.395 & 0.002 \\
\hline
\end{tabular}

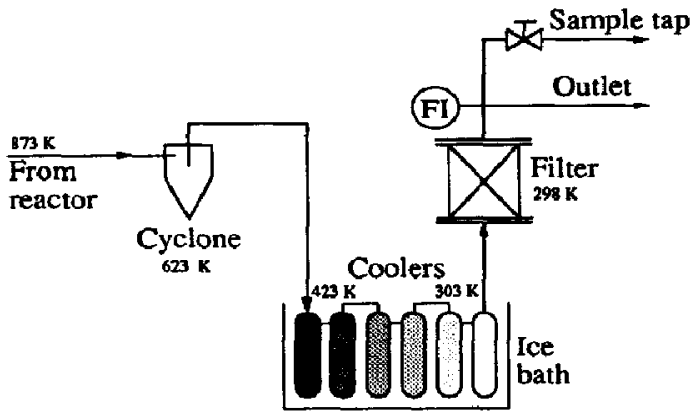

Fig. 10. The major components of the product collection system.

the reactor, the ice-cooled washing bottles shown in Fig. 10 are filled with a thick white smoke and start to collect the produced brown tar (bio-oil). The product collection system consists of a cyclone, six washing bottles placed in an ice bath and a cottonwool filter. The cyclone collects unconverted wood dust and probably some char (collected solids approximately $3 \mathrm{wt} \%$ of the wood feed) which is dragged from the reactor together with the $61 \mathrm{~s}^{-1}$ product gas flow. Connected in series with the cyclone are the six cooling bottles in which the major fraction of the tar is collected. A gas meter is used to measure the volumetric gas flow. Tar aerosols remaining in the gas flow are trapped in a cotton-wool filter. The operational definition of the pyrolysis products are related with the conditions that prevail in the product collection train. Gas is defined as the product which is non-condensible at room temperature. Tar is defined as the product that can be condensed at room temperature. The solid pyrolysis product that remains in the dead volume of the reactor is char.

At the end of each experiment the amount of tar accumulated in the collecting bottles and cotton-wool filter is measured by weighing. Samples from this gas flow are injected in a gas chromatograph for gas composition analysis, and weight determination of the produced gases. The amount of produced char is determined by measurement of the change of weight of the sand-char mixture before and after complete combustion. The duration of each experiment was limited by the quantity of inert heat carrier that could be heated to reactor temperature prior to each experiment. Each experiment lasted for $8 \mathrm{~min}$ in which a varying amount of wood dust $(0.5-2.0 \mathrm{~kg})$ and typically 
$15 \mathrm{~kg}$ sand was fed into the reactor. Apart from varying the wood-dust feed rate, the reactor volume $(3-2001)$, the reactor temperature $\left(550-700^{\circ} \mathrm{C}\right)$ and the cone rotational frequency $(6-16 \mathrm{~Hz})$ also varied. The mass accumulation of char on the rotating cone wall was typically $5 \mathrm{~g}$ per run but has yet not been related to the amount of biomass fed.

\section{RESULTS}

Three different models have been proposed in the previous sections to describe the wood-dust flow. In combination with the single particle conversion model, the wood-dust conversion at the reactor exit $\xi_{w, 1}$ can be calculated. This exit conversion can then be used in the CISTR model to predict the distribution of the pyrolysis products leaving the reactor. As a result of the calculations, the weight fractions of the pyrolysis products gas, tar and char by the CISTR model are obtained. In the next sub-section (6.1) results of simulations for various conditions will be presented first, concerning the residence time of particles in the rotating cone reactor and the corresponding degree of conversion. Then, in section 6.2, results of product distribution measurements will be discussed and compared with findings of the reactor model.

\subsection{Particle flow and conversion simulations}

Figure 11 shows the calculated residence time of a bouncing sand particle (curve $1 \mathrm{~A}$ ) as a function of the cone rotational speed. The bouncing flow model uses the assumption of equal sand and wood-dust velocities. Consequently, the calculated sand residence time is equal to the wood-dust residence time. It appears that this residence time is only slightly dependent on the cone rotational speed because the sand particles spend a minor part of their residence time in the bottom reactor volume where they are accelerated by collisions with the rotating reactor wall. The number of collisions of a bouncing particle with the cone wall per particle passage is dependent on the cone rotational frequency and varies between 10 and 100 collisions. This discrete collision behaviour causes the angularity of the residence time curve in Fig. 11.

The sliding flow model can he used to calculate the residence time of the wood-dust particles. Results of these calculations are also given in Fig. 11 which shows the residence time of sliding wood-dust particles as a function of the cone rotational speed for different particle diameters (curves $1,2,3,4$ ). A higher cone rotation frequency results in a smaller particle residence time in the rotating cone reactor due to the higher cone wall velocity which is imposed on the particles. The difference between curves 1-4 in Fig. 11 illustrates the effect of the sliding particle diameter: the smallest particles (curve $1,100 \mu \mathrm{m}$ ) have the longest residence time. This can be explained as follows: the only component of the gas-phase velocity vector is the one in the rotational direction $\phi$. Viscous forces that act on the particles tend to reduce the velocity difference between the particles and the gas phase. This results in a damping of the upward velocity component ( $r$-direction) of the particles and hence tends to increase the particle residence time $\tau_{p}$. Small particles remain in the reactor for a longer period due to the relatively strong radial particle velocity damping by the viscous force. This viscous force on a unit particle mass increases with a decreasing particle diameter due to an increase of the specific surface area on which the viscous shear forces act.

Combination of the above-presented bouncing particle model (including the corresponding heat transfer correlation) with the previously formulated single particle conversion model allows us to calculate the wood conversion in the reactor as a function of the local position $r$ (see Fig. 2). Figure 12 has been

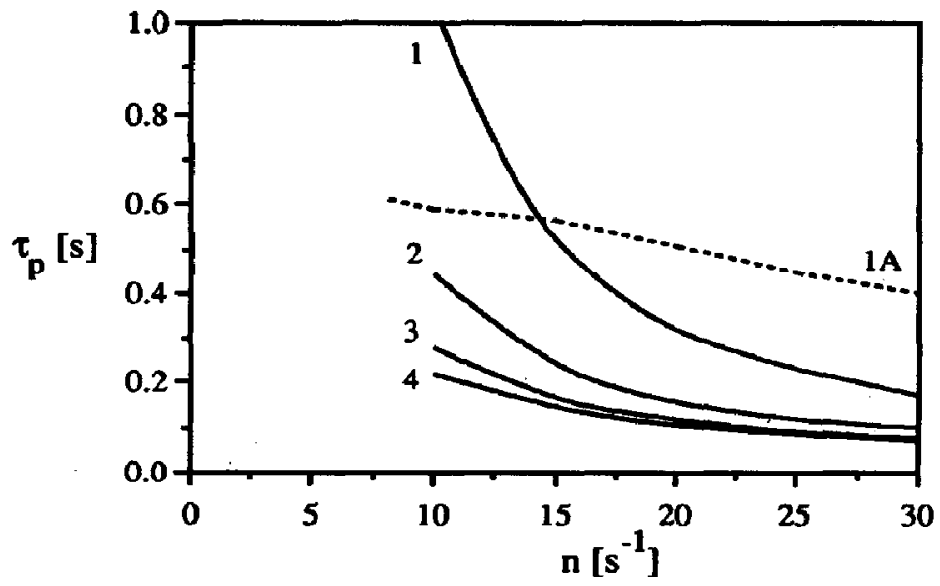

Fig. 11. Residence time of the particles inside the rotating cone reactor as a function of the cone rotation frequency according to the sliding flow model (curves $1,2,3,4$ ) and the bouncing flow model (curve 1A). Wood-dust particle diameters used in the sliding flow simulations are coupled with the curves according to: $1,100 \mu \mathrm{m} ; 2,200 \mu \mathrm{m} ; 3,300 \mu \mathrm{m} ; 4,400 \mu \mathrm{m}$. Other sliding flow parameters are: $\mu=0.9$ and $T=25^{\circ} \mathrm{C}$. Parameters of the bouncing flow model are: $\mu=0.4 ; \varepsilon=0.95 ; \beta=0.005 \mathrm{rad} ; d_{p, \text { sand }}=1 \mathrm{~mm}$ and $T=25^{\circ} \mathrm{C}$. 


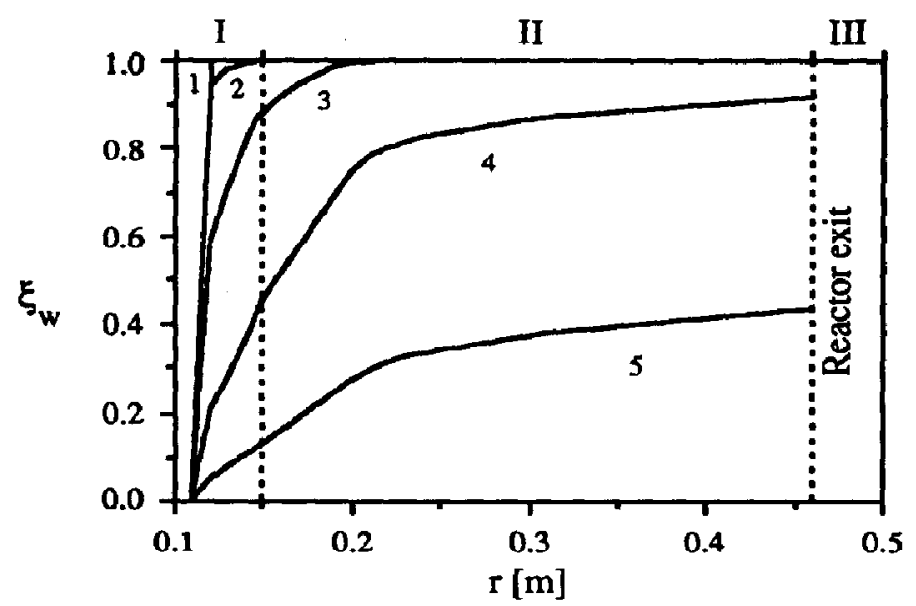

Fig. 12. Wood-dust conversion as a function of the radial position on the cone wall, for five different reactor temperatures according to the bouncing flow model. Temperatures used in the simulations are: 1 , $700^{\circ} \mathrm{C} ; 2,650^{\circ} \mathrm{C} ; 3,600^{\circ} \mathrm{C} ; 4,550^{\circ} \mathrm{C} ; 5,500^{\circ} \mathrm{C}\left(\mu=0.4, \varepsilon=0.95, \beta=0.005 \mathrm{rad}, d_{p}=100 \mu \mathrm{m}, d_{p, \text { sand }}=1 \mathrm{~mm}\right.$ and $n=11 \mathrm{~Hz}$ ).

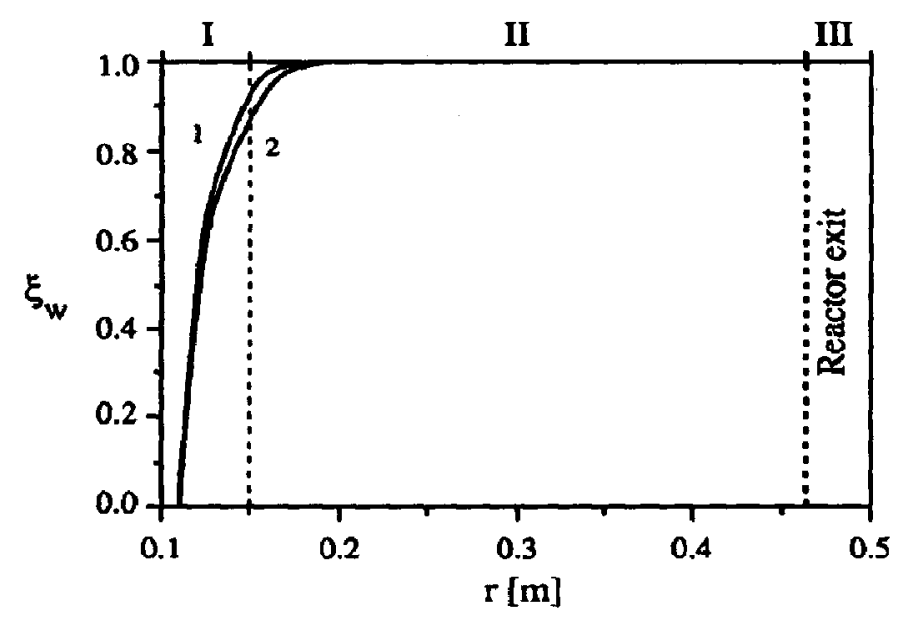

Fig. 13. Wood-dust conversion as a function of the radial position on the cone wall, for two different cone rotation frequencies according to the bouncing flow model. Rotation frequencies used in the simulations are: $1,5 \mathrm{~Hz}, 2,20 \mathrm{~Hz}\left(\mu=0.4, \beta=0.005, \varepsilon=0.95, d_{p}=100 \mu \mathrm{m}, d_{p \text {, sand }}=1 \mathrm{~mm}\right.$ and $\left.T=600^{\circ} \mathrm{C}\right)$.

divided into three parts according to the geometry of the reactor which is presented in Fig. 6. Part I $(0.1<r<0.15 \mathrm{~m})$ represents the bottom volume of the reactor. Part II $(0.15<r<0.46 \mathrm{~m})$ corresponds to the annular volume and part III $(r>0.46 \mathrm{~m})$ to the dead volume around the rotating cone. The same set-up has been used in Figures 13,14 and 15. Results of simulations in which the reactor temperature has been varied from 500 to $700^{\circ} \mathrm{C}$ are presented in Fig. 12. From this figure it can be deduced that the wood-dust conversion is incomplete at low reactor temperatures $\left(500\right.$ and $550^{\circ} \mathrm{C}$ ). Heating of the biomass particles $\left(d_{p}=100 \mu \mathrm{m}\right)$ occurs between $r=0.1$ and $0.115 \mathrm{~m}$, that is immediately after their introduction into the bottom space of the reactor. This corresponds to the part of the horizontal axis in Fig. 12 where the conversion degree is zero. Clearly, the biomass conversion is limited by the biomass decomposition kinetics because heating of the particles only occurs in a small part of the bottom volume of the reactor.

Results of simulations for two different cone rotational frequencies $(5$ and $20 \mathrm{~Hz}$ ) are given in Fig. 13. For a reactor temperature of $600^{\circ} \mathrm{C}$ and rotation frequencies up to $20 \mathrm{~Hz}$ the wood-dust conversion is largely completed already inside the bottom volume of the reactor. At temperatures lower than $550^{\circ} \mathrm{C}$, a partial conversion of the pine wood particles inside the reactor volume is obtained because of the decreased chemical conversion rate. This results in a decreased bio-oil yield, especially for high 


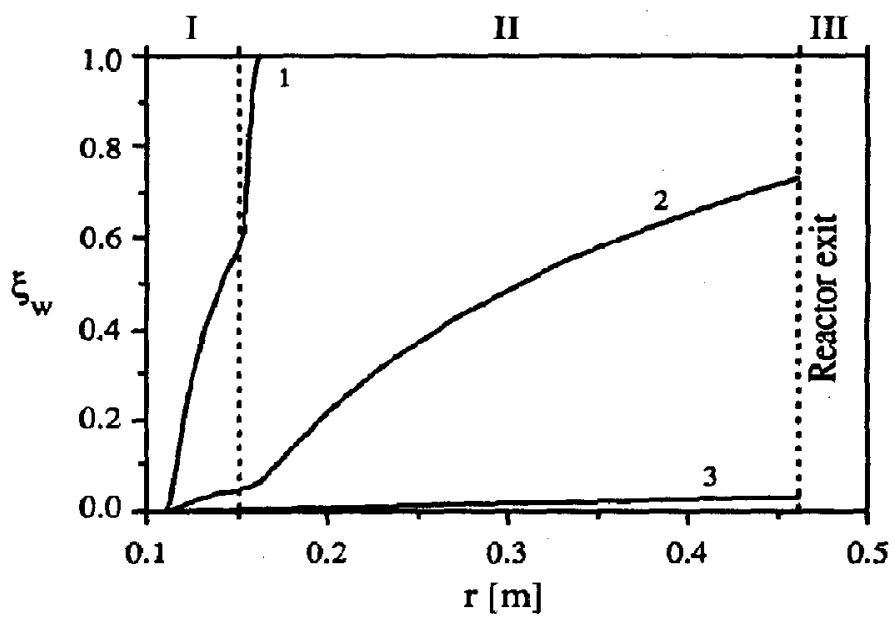

Fig. 14. Wood-dust conversion as a function of the radial position on the cone wall, for three different reactor temperatures according to the sliding flow model. Temperatures used in the simulations are: $1,600^{\circ} \mathrm{C} ; 2,500^{\circ} \mathrm{C} ; 3,400^{\circ} \mathrm{C}\left(\mu=0.9, d_{p}=100 \mu \mathrm{m}\right.$ and $\left.n=11 \mathrm{~Hz}\right)$.

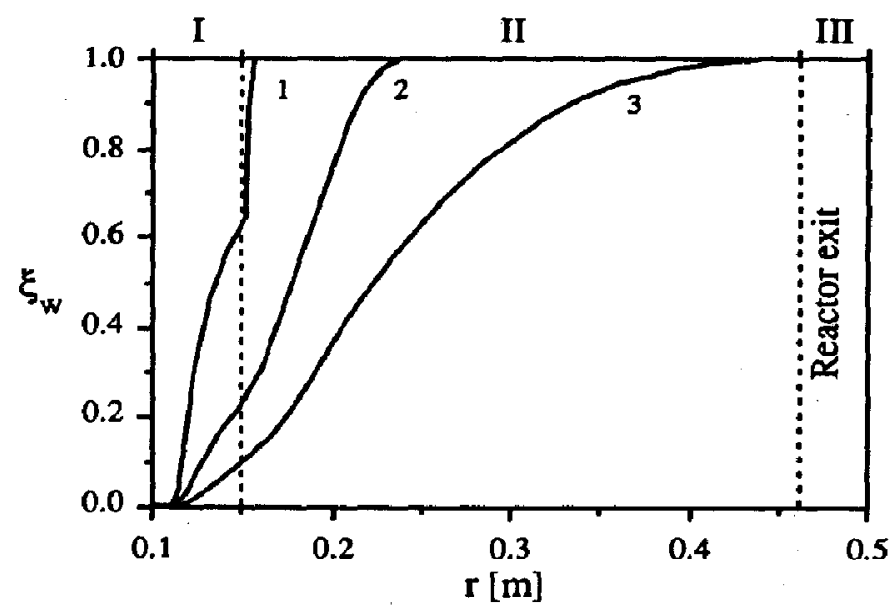

Fig. 15. Wood-dust conversion as a function of the radial position on the cone wall, for three different cone rotation frequencies according to the sliding flow model. Rotation frequencies used in the simulations are: $1,10 \mathrm{~Hz} ; 2,20 \mathrm{~Hz} ; 3,30 \mathrm{~Hz}\left(\mu=0.9, d_{p}=100 \mu \mathrm{m}\right.$ and $\left.T=600^{\circ} \mathrm{C}\right)$.

rotational frequencies or short particle residence times inside the reactor volume.

The single particle conversion model can also be solved while using the results of the sliding wood-dust flow model plus the proper value of the heat transfer coefficient. Results of simulations for three different temperatures are presented in Fig. 14 as a plot of the wood conversion against the local position along the rotating cone wall. It should be noticed that the discontinuities in the curves shown correspond to the position where the particle passes the boundary from bottom to annular space volume. Again, the wooddust conversion appears to be incomplete for reactor temperatures below $600^{\circ} \mathrm{C}$. Results of simulations in which the cone rotational frequency has been varied are presented in a similar plot shown in Fig. 15.
At $600^{\circ} \mathrm{C}$, a complete wood-dust conversion at the reactor exit is achieved for all frequencies used in the simulations.

Figure 16 shows the conversion at the reactor exit as a function of the reactor temperature for the three different particle flow models and wood-dust particles of $100 \mu \mathrm{m}$. It is a result of calculations similar to those used for the construction of the diagrams in Figs 12 and 14. For sticking conditions (line 1 in Fig. 16), it is obvious that the particle conversion at the exit must always be one, independent of the applied temperature. The two other models (line 2 for sliding and line 3 for bouncing flow) predict an exit conversion increasing from 0.1 to 1 for reactor temperatures between 450 and $600^{\circ} \mathrm{C}$. Because bouncing particles flow faster through the reactor than sliding wood-dust particles 


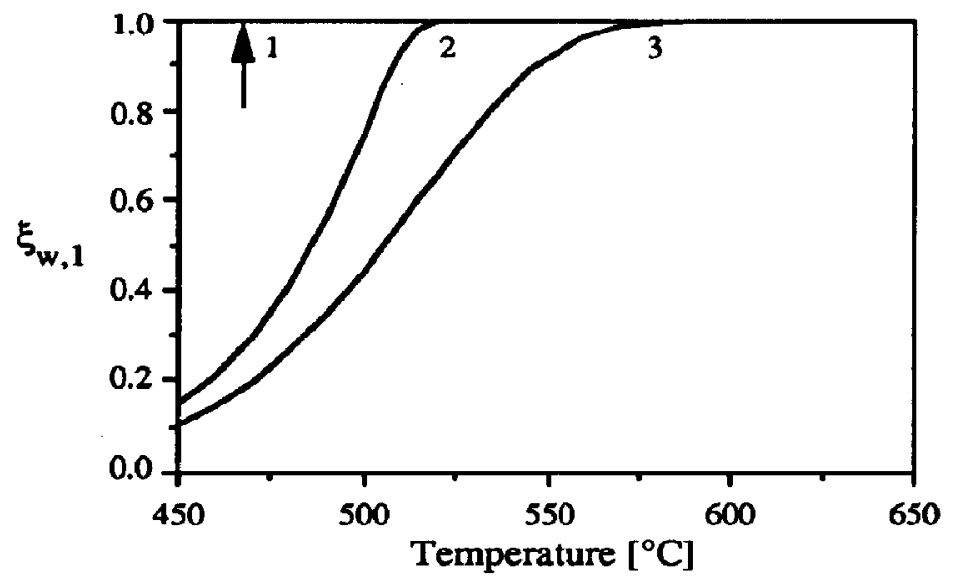

Fig. 16. The wood conversion at the exit of the annular reactor volume as a function of temperature according to three different wood-dust flow models. The simulation models used are: 1, sticking model; 2 , sliding flow model; 3 , bouncing flow model $\left(n=11 \mathrm{~Hz}, V_{r}=31, d_{p}=100 \mu \mathrm{m}\right.$ and $\left.d_{p \text { sand }}=1 \mathrm{~mm}\right)$.

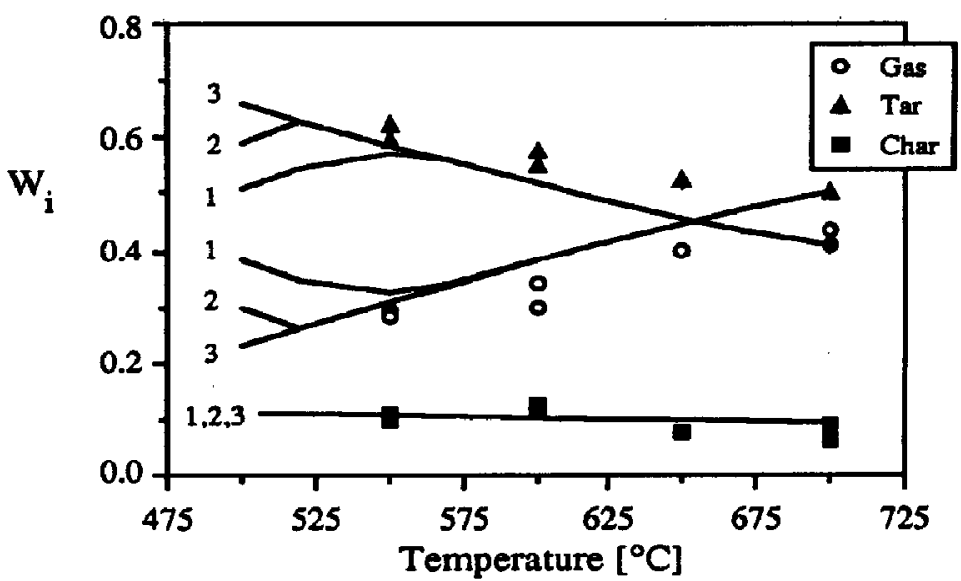

Fig. 17. The weight fraction of each pyrolysis product as a function of the reactor temperature according to three different wood-dust flow models. The solid curves correspond with the model predictions. The simulation models used are: 1 , bouncing flow model; 2 , sliding flow model; 3, sticking model ( $n=11 \mathrm{~Hz}$, $V_{r}=31$, wood-dust feed rate $=2 \mathrm{~g} \mathrm{~s}^{-1}, d_{p}=100 \mu \mathrm{m}$ and $d_{p, \text { sand }}=1 \mathrm{~mm}$ ).

at a rotation frequency of $10 \mathrm{~Hz}$, their exit conversion (line 3) is always smaller than the one for sliding particles (line 2).

\subsection{Predicted and measured product distribution}

If the results presented in Fig. 16 are introduced in the CISTR gas-phase model to calculate the resulting product distribution, the lines presented in Fig. 17 are obtained. This diagram is a plot of the weight fractions $W_{i}$ of gas, tar and char versus the applied reactor temperature. Apart from the lines predicted by the 2-CISTR model, the diagram also contains the data points obtained experimentally. Let us first consider the model calculations represented by lines 1 to 3 . With respect to gas and tar formation, Fig. 17 shows that differences between the three model lines 1 to 3 only occur at reactor temperatures below $550^{\circ} \mathrm{C}$, that is for conditions at which bouncing (line 1) and sliding (line 2) particles leave the annular reactor space partially unconverted. All models predict a char yield of $10 \mathrm{wt} \%$ because this value is introduced in the kinetic scheme which has already been mentioned in the particle conversion model. The correspondence of the three models at higher temperatures is based on the fact that all three flow models predict a complete wood conversion in the cone reactor at these temperatures. Experimental data in Fig. 17 show a more severe cracking of all products at higher temperatures which results in less tar formation and more gas production. This behaviour is predicted also by the models; in fact, the agreement between theoretical and experimental results is quite satisfactory. 


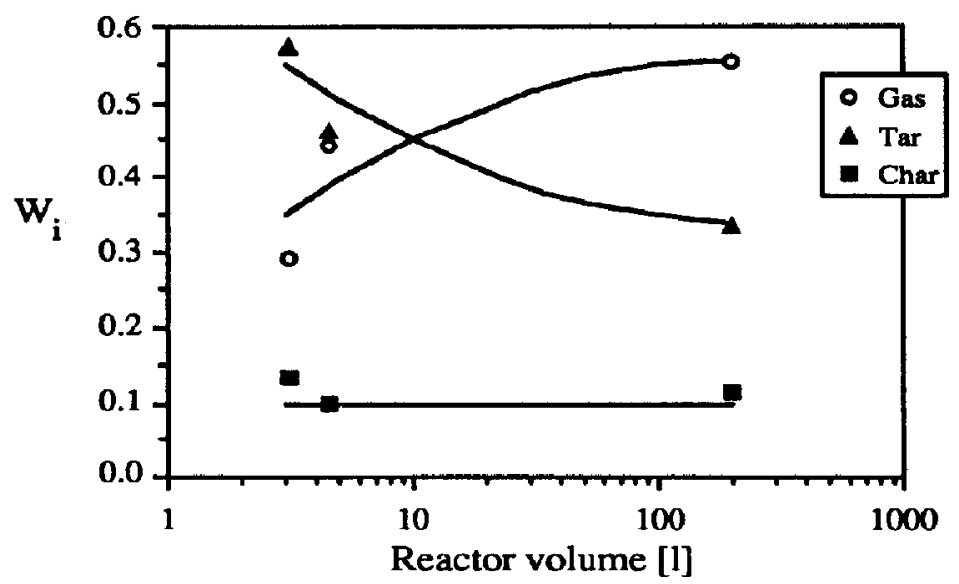

Fig. 18. Weight fraction of each pyrolysis product as a function of the reactor volume. The solid curves correspond with the model predictions $\left(n=11 \mathrm{~Hz}, T=600^{\circ} \mathrm{C}\right.$, wood-dust feed rate $=3 \mathrm{~g} \mathrm{~s}^{-1}, d_{p}=100 \mu \mathrm{m}$ and $d_{p, \operatorname{sand}}=1 \mathrm{~mm}$ ).

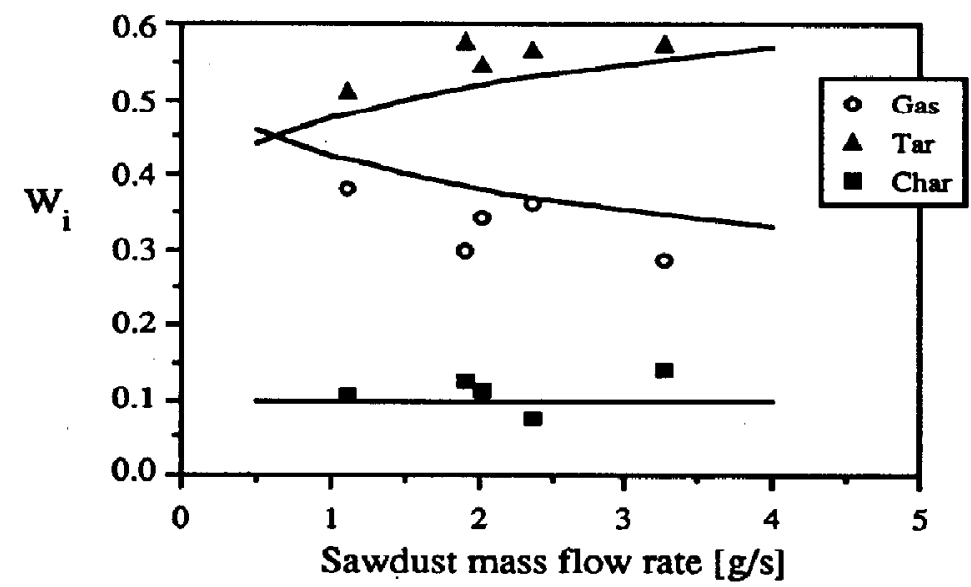

Fig. 19. Weight fraction of each pyrolysis product as a function of the wood-dust flow rate into the reactor. The solid curves correspond with the model predictions $\left(n=11 \mathrm{~Hz}, T=600^{\circ} \mathrm{C}, V_{r}=31, d_{p}=100 \mu \mathrm{m}\right.$ and $\left.d_{p . \text { sand }}=1 \mathrm{~mm}\right)$.

Determination of the wood-dust flow behaviour cannot be fully based on the product composition measurements at the reactor exit. Suppose that half of the wood dust sticks to the cone wall and half of the wood dust flows according to the bouncing flow model, then the combined effect on the product distribution will resemble the predictions of the sliding flow model (see also Fig. 17). A distinction between the flow models, in terms of a difference in the predicted product distribution, only occurs for partially converted particles. Because of the nearly complete sawdust conversion in most of the experiments the experimental data are not precise enough to discriminate between the flow models. However, if the flow behaviour of a certain material is known beforehand, one of the presented flow models can be applied.

For wood-dust particles with a mean diameter of $100 \mu \mathrm{m}$ the three flow models predict a complete wood conversion for the experiments in which the reactor volume, the wood-dust mass flow rate and the cone rotation frequency have been varied (Figs 18-21). This implies that for a certain wood-dust feed rate the 2-CISTR model always predicts the same pyrolysis product distribution at the reactor exit. Figure 18 shows the product distributions obtained in experiments, carried out at $600^{\circ} \mathrm{C}$, for three different values of the reactor volume $V_{r}$. A value of 31 corresponds to the annular space volume with a distance of $3 \mathrm{~mm}$ between the stagnant inner cone and the rotating one. $V_{r}=4.51$ was realized by increasing the annular space distance to $5 \mathrm{~mm}$. Finally, the extreme value of $200 \mathrm{l}$ was obtained by removing the entire inner cone and utilizing also the otherwise decoupled dead volume. The vapour residence times corresponding to the above reactor volumes are $0.49,0.65$ and $30 \mathrm{~s}$ respectively for a wood-dust feed rate of $2 \mathrm{~g} \mathrm{~s}^{-1}$ and complete wood-dust conversion. As illustrated by Figs 18 and 19 the vapour residence time is very important 


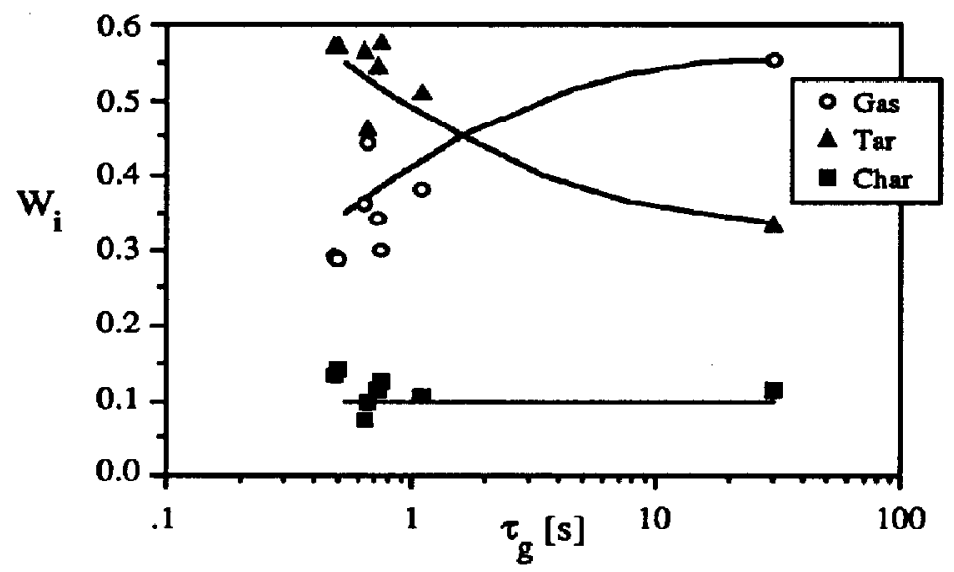

Fig. 20. The weight fraction of each pyrolysis product as a function of the gas-phase residence time in the rotating cone reactor, from the combined measurements of Figs 18 and 19. [The calculation of the gas-phase residence time is based on eq. (38).]

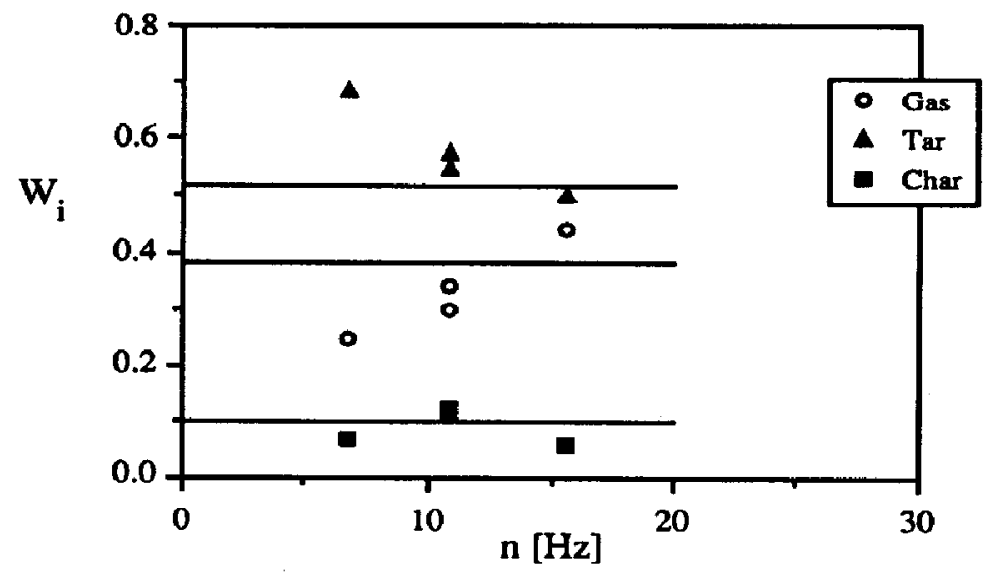

Fig. 21. The weight fraction of each pyrolysis product as a function of the cone rotation frequency. The solid curves correspond with the model predictions (wood-dust feed rate $=2 \mathrm{~g} \mathrm{~s}-1, T=600^{\circ} \mathrm{C}, V_{r}=3 \mathrm{l}$ ).

for the eventual product composition. According to Wagenaar (1994) cracking of the primary produced tars is completed within $3 \mathrm{~s}$ at a temperature of $600^{\circ} \mathrm{C}$; a vapour residence time of $1 \mathrm{~s}$ would allow a $63 \%$ conversion of the primary tars to gas.

Figure 18 shows that the weight fraction tars (bio-oil including $\mathrm{H}_{2} \mathrm{O}$ ) produced in the experiment at $V_{r}=31(t=0.49 \mathrm{~s})$ is approximately $57 \%$. This weight fraction corresponds quite well with the prediction of the 2-CISTR model $(55 \%)$ which would mean that the wood conversion in the reactor must have been practically complete. It means also that there is no marked exchange of gas and tars between the reactor volume and the large dead volume of the surrounding oven. Unfortunately, a direct proof for complete wood conversion cannot be provided; the pyrolysis unit has no provision for sampling solids from the reactor volume.

An increase in the wood-dust feed rate results in an increased volumetric flow of the produced vapours or a reduction of the vapour residence time. The product composition as a function of the wood-dust feed rate is presented in Fig. 19. It is evident that an increase in the wood-dust feed rate results in an increase in the production of tars because the time available for tar-cracking is reduced in this way. At $600^{\circ} \mathrm{C}$ the ultimate tar yield should be $72 \mathrm{wt} \%$ on d.a.f. wood basis (Wagenaar et al., 1993). Since both the wood-dust feed rate and the reactor volume affect the residence time of the pyrolysis vapours in the reactor, the product distributions of Figs 18 and 19 can be presented together in a single plot of $W_{i}$ versus $\tau_{g}$ by using eq. (38). The result is illustrated in Fig. 20 and is consistent with the above discussion. For a complete wood-dust conversion in the reactor, the wood decomposition vapours are only released in reactor volume $V_{1}$. The residence time of the produced vapours (gases and tars) in the reactor is then determined by:

$$
\tau_{g}=V_{1} / \phi_{V_{1}}
$$


Plotted on the horizontal axis in Fig. 20 is the gas-phase residence time defined by eq. (38). The use of this parameter enables the combination of measurements in which the reactor volume has been varied together with measurements in which the sawdust feed rate has been varied in a single graph of the product distribution as function of the gas-phase residence time.

The rotation frequency of the cone is a process parameter which can be varied over a considerable range. Results from particle flow simulations given in Figs 13 and 15 indicate a complete wood-dust conversion in the reactor volume at $600^{\circ} \mathrm{C}$ and for cone rotation frequencies varying between 5 and $20 \mathrm{~Hz}$. As a consequence, the predicted product distribution is independent of the cone rotational frequency for that temperature. However, the experimental data points presented in Fig. 21 show a tar production which increases rapidly for lower cone rotational frequencies. This observation can only be explained by a deviation of ideal gas-phase mixing in the reactor volume at low cone rotation frequencies. If at lower rotation frequencies the pyrolysis vapours are mainly produced in the bottom volume and not mixed prior to removal with the annular volume, the volume occupied by the vapours is reduced and hence the effective residence time of the vapours in the hot reactor will be reduced. Figure 21 again shows the relevance of removing the tar vapours out of the hot reaction zone as fast as possible. At a cone rotation frequency of $7 \mathrm{~Hz}$ the tar yield is $70 \mathrm{wt} \%$ on d.a.f. basis which is close to the maximum possible yield of $72 \mathrm{wt} \%$ at $600^{\circ} \mathrm{C}$ observed by Wagenaar and coworkers (1993).

\subsection{Additional experiments}

Figure 22 shows a pyrolysis product composition bar diagram for soft wood, hard wood and rice husks.
The tar phase is divided into organic liquids fraction and water. Although the collection efficiency of hard wood and rice husk pyrolysis products was less than $90 \mathrm{wt} \%$, a trend of decreasing tar yields could be observed from soft wood pyrolysis towards rice husk pyrolysis. Rice husks contain more minerals which results in a larger ash production as shown in Fig. 22. The composition of each feedstock is given in Table 1. Soft wood, hard wood and rice husks could all equally well be processed in the rotating cone pyrolysis reactor. Char deposition on the cone wall was less than $5 \mathrm{~g}$ for each run although a time dependent char accumulation has not been investigated yet. The fluffy char was mainly located at the sharp transition of the horizontal cone bottom and the inclined cone wall.

Tar (bio-oil) which has been produced in the pine wood pyrolysis process has a density of $1,200 \mathrm{~kg} \mathrm{~m}^{-3}$ and a viscosity of $80 \mathrm{cP}$ at room temperature. Analysis of the water content of the produced bio-oils showed that $15 \mathrm{wt} \%$ of wood was converted to water in each pine wood pyrolysis experiment. The heat of combustion of pine wood pyrolysis oil varies between 15 and $19 \mathrm{MJ} \mathrm{kg}^{-1}$. Fossil fuels have a typical heat of combustion of $40 \mathrm{MJ} \mathrm{kg}{ }^{-1}$ and this value is higher compared to that of bio-oil because bio-oils can contain up to $50 \mathrm{wt} \%$ oxygen. It should be realized, however, that biomass can be regarded as a partially oxidized feedstock. Advantages of bio-oil energy carriers are that they can be obtained from a sustainable feedstock and using biomass as a fuel does not contribute to atmospheric carbon-dioxide accumulation.

\section{CONCLUSIONS}

The single particle conversion model (which includes a particle flow model) predicts a partial conversion of the biomass particles for high cone rotational

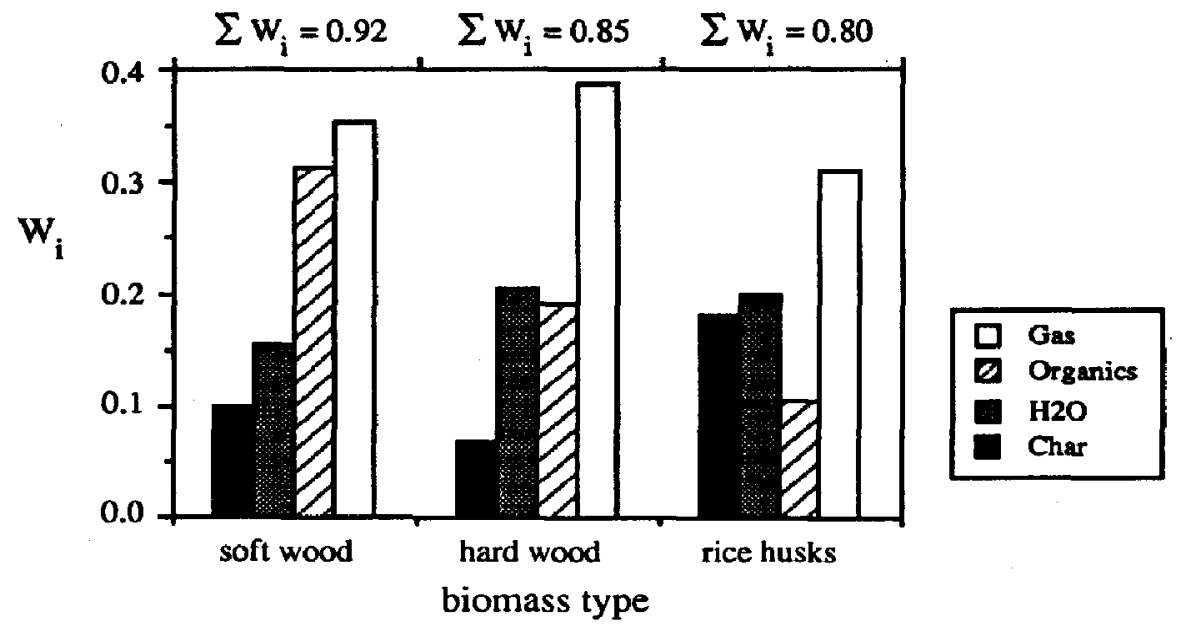

Fig. 22. The distribution of flash pyrolysis products obtained from the RCR of several different types of biomass. The process conditions used were: a reactor temperature $600^{\circ} \mathrm{C}$, a wood-dust feed rate of $2 \mathrm{~g} \mathrm{~s}^{-1}$, a cone rotational frequency of $11 \mathrm{~Hz}$ and a reactor volume of 31 . Organics is bio-oil from which all water has been removed. 
frequencies or for low reactor temperatures. Results from pyrolysis experiments in the rotating cone reactor show that $100 \mu \mathrm{m}$ wood-dust particles are decomposed completely when they are introduced into a reactor having a temperature between 550 and $700^{\circ} \mathrm{C}$ and at a typical cone rotational frequency of $10 \mathrm{~Hz}$. The gas-phase reactor model is able to predict the correct pyrolysis product distribution, even in cases of partial wood conversion in the reactor volume. All experimental results have been obtained for reactor conditions allowing complete wood conversion in the reactor volume. The product distribution is then only dependent on the amount of secondary tar cracking.

A maximum tar yield of $70 \mathrm{wt} \%$ (on d.a.f. wood) can be achieved with the present rotating cone reactor. Experiments in which more than $55 \mathrm{wt} \%$ of tar is produced can only be explained by a nearly complete pine wood-dust conversion in the reactor volume and a negligible vapour exchange flow between the reactor volume and the dead volume (see Fig. 6).

The residence time of the produced vapours should be kept below $1 \mathrm{~s}$ to minimize the secondary tar cracking reactions at $600^{\circ} \mathrm{C}$. This is realized in the present rotating cone reactor by insertion of a volume blocking inner cone meant to reduce the reactor volume. In case the gas-phase residence time is deliberately increased to $30 \mathrm{~s}$ a considerable amount of tar is still produced: stable tars can account for up to $30 \mathrm{wt} \%$ of the produced pyrolysis products after severe thermal vapour cracking. However, these severely cracked tars are more aqueous because $15 \mathrm{wt} \%$ of wood is converted to water in each pine wood pyrolysis experiment.

If the wood-dust conversion in the reactor volume is complete, the predicted pyrolysis product distribution is independent of the wood-dust flow behaviour. Results of the particle flow and conversion simulations can be used to derive the reactor conditions for which a complete wood-dust conversion is achieved.

For the present reactor geometry the models predict complete woud-dust conversion in the reactor volume if (1) the reactor temperature is higher than $600^{\circ} \mathrm{C}$ and (2) the cone rotational frequency is less than $30 \mathrm{~Hz}$.

Determination of the wood-dust flow behaviour cannot be fully based on the product composition measurements at the reactor exit. Suppose that half of the wood dust sticks to the cone wall and half of the wood dust flows according to the bouncing flow model, then the combined effect on the product distribution will resemble the predictions of the sliding flow model (see also Fig. 17).

Three different types of biomass feedstock have been processed successfully in the rotating cone reactor. In all cases char formation on the reactor wall was negligible.

Acknowledgements-This investigation was supported by the CEC-Joule programme and NOVEM. The authors also acknowledge M. J. Koetsier and R. Meijer for their assistance in this work.

\begin{tabular}{|c|c|}
\hline \multicolumn{2}{|r|}{ NOTATION } \\
\hline$a$ & acceleration, $\mathrm{m} \mathrm{s}^{-2}$ \\
\hline$A$ & surface, $\mathrm{m}^{2}$ \\
\hline $\begin{array}{l}B i_{p} \\
C\end{array}$ & $\begin{array}{l}\text { particle Biot number }\left(\alpha_{p} d_{p} / \lambda_{p}\right) \\
\text { concentration, mol m-3 }\end{array}$ \\
\hline$C_{i, 1}$ & $\begin{array}{l}\text { concentration of products in the reactor } \\
\text { volume, mol } \mathrm{m}^{-3}\end{array}$ \\
\hline$C_{i, 2}$ & $\begin{array}{l}\text { concentration of products in the dead volume } \\
\text { mol m-3 }\end{array}$ \\
\hline$C_{d}$ & drag coefficient \\
\hline$C_{p}$ & heat capacity, $\mathrm{J} \mathrm{kg}^{-1} \mathrm{~K}^{-1}$ \\
\hline$d_{p}$ & $\begin{array}{l}\text { average wood-dust particle diameter, } \mathrm{m} \\
\text { force, } \mathrm{N}\end{array}$ \\
\hline $\begin{array}{l}g \\
H\end{array}$ & $\begin{array}{l}\text { gravitational force per unit mass, } \mathrm{m} \mathrm{s}^{-2} \\
\text { heat of the wood decomposition reaction } \\
\mathrm{J} \mathrm{kg}^{-1}\end{array}$ \\
\hline$J_{n}$ & $\begin{array}{l}\text { impulse in the direction normal to the cone } \\
\text { wall, } \mathrm{kg} \mathrm{m} \mathrm{s}\end{array}$ \\
\hline$J_{p}$ & $\begin{array}{l}\text { impulse in the direction tangential to the cone } \\
\text { wall, } \mathrm{kg} \mathrm{m} \mathrm{s}\end{array}$ \\
\hline$k$ & first-order rate constant, $s^{-1}$ \\
\hline$m$ & mass, $\mathbf{k g}$ \\
\hline$M$ & molar mass, $\mathrm{kg} \mathrm{mol}^{-1}$ \\
\hline$N$ & molar flow, mol s -1 \\
\hline$N_{\theta}$ & $\begin{array}{l}\text { unit vector perpendicular to the cone wall } \\
\text { particle normal force, } N\end{array}$ \\
\hline$N u_{p}$ & particle Nusselt number $\left(\alpha d_{p} / \lambda_{g}\right)$ \\
\hline $\begin{array}{l}P \\
P r\end{array}$ & $\begin{array}{l}\text { unit vector tangentially to the cone wall } \\
\text { Prandtl number }\left(v_{g} \rho_{g} C_{p, g} / \lambda_{g}\right)\end{array}$ \\
\hline$R_{i, 1}$ & $\begin{array}{l}\text { molar production of vapours in the reactor } \\
\text { volume, mol s }\end{array}$ \\
\hline$R_{i, 2}$ & $\begin{array}{l}\text { molar production of vapours in the dead } \\
\text { volume, mol s}\end{array}$ \\
\hline $\begin{array}{l}\operatorname{Re}_{p} \\
T\end{array}$ & $\begin{array}{l}\text { particle Reynolds number }\left(\left|v_{p}-v_{g}\right| d_{p} / v_{g}\right) \\
\text { temperature, } \mathrm{K}\end{array}$ \\
\hline$v$ & velocity, $\mathrm{m} \mathrm{s}^{-1}$ \\
\hline$V$ & volume, $\mathrm{m}^{3}$ \\
\hline$V_{1}$ & reactor volume, $\mathrm{m}^{3}$ \\
\hline$V_{2}$ & dead volume, $\mathrm{m}^{3}$ \\
\hline$w_{i}$ & \\
\hline
\end{tabular}

\section{Greek letters}

$\alpha_{p} \quad$ gas-to-particle heat transfer coefficient, $\mathrm{W} \mathrm{m}^{-2} \mathrm{~K}^{-1}$

$\beta$ deflection angle, rad

$\varepsilon \quad$ coefficient of restitution

$\phi_{v} \quad$ volume flow, $\mathrm{m}^{3} \mathrm{~s}^{-1}$

$\phi_{v 0} \quad$ volume vapour production, $\mathrm{m}^{3} \mathrm{~s}^{-1}$

$\phi_{v, 1}$ volume flow at the exit of the reactor volume, $\mathrm{m}^{3} \mathrm{~s}^{-1}$

$\phi_{v, 2}$ volume flow at the exit of the dead volume, $\mathrm{m}^{3} \mathrm{~s}^{-1}$

mass flow, $\mathrm{kg} \mathrm{s}^{-1}$

$\lambda$

thermal conductivity, $\mathrm{W} \mathrm{m}^{-1} \mathrm{~K}^{-1}$

coefficient of friction

kinematic viscosity, $\mathrm{m}^{2} \mathrm{~s}^{-1}$

stoichiometric coefficient

density, $\mathrm{kg} \mathrm{m}^{-3}$

mass selectivity coefficient

thermal contact resistance length, eq. (29), m 
$\tau \quad$ residence time, $s$

$\omega$ cone angular speed, rad $s^{-1}$

$\xi_{w}$ wood conversion (on mass fraction basis)

$\xi_{w, 1}$ wood conversion at the reactor exit $(r=0.46 \mathrm{~m})$

\section{Subscripts}

0 initial

1 primary wood decomposition reaction

2 secondary tar cracking reaction

c char

$g$ primary produced gas

$g$ gas produced by primary tar cracking

$p \quad$ parlicle

$r$ reactor

$t \quad$ primary produced tar

$t^{*} \quad$ stable tar produced by primary tar cracking

$w \quad$ wood or cone wall

$\boldsymbol{R}$ cylindrical coordinate, radial direction

$r$ spherical coordinate, radial direction

$\theta \quad$ spherical coordinate, $\theta$-angle direction

$\phi \quad$ spherical coordinate, $\phi$-angle direction

\section{REFERENCES}

Ambari, A., Gauthier-Manuel, B. and Guyon, E., 1984, Wall effects on a sphere translating at constant velocity. $J$. Fluid Mech. 149, 235.

Antal, M. J., 1983, Biomass pyrolysis: a review of the literature. Part 1: carbohydrate pyrolysis. Adv. Solar Energy 1, 61.

Arpiainen, V. and Lappi, M., 1989, Products from the flash pyrolysis of peat and pine bark. J. Anal. Appl. Pyrol. 16, 355.

Augenstein, D. A. and Hogg, R., 1974, Friction factors for powder flow. Powder. Techn. 10, 43.

Bridgwater, A. V. and Bridge, S. A., 1991, A review of biomass pyrolysis and pyrolysis technologies, in Biomass Pyrolysis Liquids Upgrading and Utilisation, p. 11. Elsevier Science Publishing Co., New York.

Deglise, X., Richard, C., Rolin, A. and Francois, H., 1981, Fast pyrolysis of lignocellulosic materials at short residence time, in Energy from Biomass, I st EC Conference, Brighton, England, Nov. 1980 (Edited by W. Palz, P. Chartier and D. O. Hall), p. 548, Applied Science Publishers Ltd, London.

Diebold, J. P., 1985, The cracking kinetics of depolymerized biomass vapours in a continuous tubular reactor. MSc. thesis, Colorado School of Mines, Golden, $\mathrm{CO}$.

Gorton, C. W., Kovac, R. J., Knight, J. A. and Nygaard, T. I., 1990, Modeling pyrolysis oil production in an entrained-flow reactor. Biomass, 21, 1 .
Graham, R. G., Freel, B. A. and Bergougnou, M. A., 1988, The production of pyrolytic liquids, gas and char from wood and cellulose by fast pyrolysis, in Research in Thermochemical Biomass Conversion, p. 629. Elsevier Applied Science, New York.

Liden, A. G., Berruti, F. and Scott, D. S., 1988, A kinetic model for the production of liquids from the fiash pyrolysis of biomass. Chem. Engng. Comm. 65, 27.

Matsumoto, S. and Saito, S., 1970, On the mechanism of suspension of particles in horizontal pneumatic conveying: Monte Carlo simulation based on the irregular bouncing model. J. Chem. Engng Jpn 3, 83.

Patton, J. S., Sabersky, R. H. and Brennen, C. E., 1986, Convective heat transfer to rapidly flowing granular materials. Int. J. Heat Mass Transf. 29, 1263.

Pilpel, N., 1965, Flow properties of non-cohesive powders. Chem. Proc. Engng. 46, 167.

Pyle, D. L. and Zaror, C. A., 1984, Heat transfer and kinetics in the low temperature pyrolysis of solids. Chem. Engng. Sci. 39, 147 .

Ranz, W. E. and Marshall, W. R., 1952, Evaporation from drops, Part 2. Chem. Engng Pr. 48, 173.

Rowe, P. N., 1961, Drag forces in a hydraulic model of a fluidised bed. Part 1. Trans. Instn. Chem. Engrs. 39, 43.

Roy, C., de Caumia, B., Brouillard, D. and Menard, H., 1985 , The pyrolysis under vacuum of Aspen poplar, in Fundamentals of Thermochemical Biomass Conversion, p. 237. Elsevier Applied Science, New York.

Schlünder, E. U., 1982, Particle heat transfer, in Proceedings of the 7th International Heat Transfer Conference, Munich, 1, 195.

Scott, D. S. and Piskorz, J., 1982, The flash pyrolysis of Aspen-poplar wood. Can. J. Chem. Engng. 60, 666.

Shafizadeh, F., 1985, Pyrolytic reactions and products of biomass, in Fundamentals of Thermochemical Biomass Conversion, p. 1 (Edited by R. P. Overend, T. A. Milne and L. K. Mudge), Elscvicr Applied Science.

Tsuji, Y., Shen, N. Y. and Morikawa, Y., 1989, Numerical simulation of gas-solid flows. Techn. Rep. Osaka Univ. 39, 233.

Wagenaar, B. M., 1994, The rotating cone reactor for rapid thermal solids processing. Ph.D. thesis, University of Twente, The Netherlands.

Wagenaar, B. M., Prins, W. and Van Swaaij, W. P. M., 1993. Flash pyrolysis kinetics of pine wood. Fuel Proc. Techn. 36, 291.

Wagenaar, B. M., Kuipers, J. A. M. and Van Swaaij, W. P. M. 1994a, Particle dynamics and gas phase hydrodynamics in a rotating cone reactor. Chem. Engng Sci. 49, 927.

Wagenaar, B. M., Kuipers, J. A. M., Meijer, R. and Van Swaaij, W. P. M., 1994b, A novel method for noncontact measurement of particle temperatures. A.I.Ch.E. $J$. (accepted).

Wagenaar, B. M., Kuipers, J. A. M. and Van Swaaij, W. P. M., $1994 c$, Fluoroptic measurements of the local heat transfer coefficient inside the rotating cone reactor. Chem. Engng Sci. (submitted). 